Proc. 13th Econophysics Colloquium (EC) and 9th Symposium of Physics in Economy and Social Sciences (FENS), 2017

\title{
Cyclical Properties of the Credit and Production in Selected European Countries - a Comparison of Deterministic and Stochastic Cycle Approach
}

\author{
E. LENART ${ }^{a}$ AND M. PIPIEŃ ${ }^{b, *}$
}

${ }^{a}$ Department of Mathematics, Cracow University of Economics, Cracow, Poland

${ }^{b}$ Department of Econometrics and Operations Research, Cracow University of Economics, Cracow, Poland

\begin{abstract}
We develop two nonparametric approaches to analyze the empirical properties of economic cycles. The first approach is based on almost periodically correlated time series commonly used in signal processing. Within this framework we depart from standard scheme of analysis that relies on stationarity assumption. The second approach is based on spectral analysis provided the stationarity assumption of cyclical fluctuations. We contribute to the existing literature in both, theoretical and empirical aspects. From theoretical viewpoint we develop methods of formal statistical inference about the main properties of elements of the economic cycle. In the first approach the testing procedure utilizing subsampling approach is proposed. In the second approach the method of analysis of concentration of the spectral mass is developed. Based on the monthly series of the credit aggregate and the industrial production, taken from selected European countries, we discuss the empirical properties of the credit cycle and we compare them with the production cycle. Our empirical findings show substantial diversity of the credit cycle across analysed countries. Also cyclical component in the credit series is identified much stronger than in case of the series of industrial production. Also the production cycles are much more synchronized across countries compared to the credit cycles.
\end{abstract}

DOI: 10.12693/APhysPolA.133.1371

PACS/topics: almost periodicity, spectral analysis, financial cycle, production cycle

\section{Introduction}

The global financial crisis occurring in the late 2000's has clearly shown the importance of financial factors in the business cycle of developed economies. From theoretical viewpoint this importance was highlighted many decades ago by Fisher [1] and Minsky [2], explaining this "financial effect" by existence of financial accelerator and also by the nature how debt may rise after economic booms (amplified by excessive credit) and fall unexpectedly casing serious distress. Prior to the crisis the most important questions related to the cyclical nature of economic activity concerned the real sector, making the business cycle the most important subject of inquiry. Besides some exceptions, like for example Delli Gatti et al. [3] the pre-crisis paradigm was dominated by opinion that fluctuations of the financial system, observed as financial booms and busts, have side effects; see Drehmann et al. [4]. Thus the notion of the financial cycle was not represented in the postwar mainstream of economy.

After the global financial crisis occurred in last decade a growing number of papers investigated financial markets and banking sector in theoretical and econometrics modelling. Cúrdia and Woodford [5] considered modified Taylor rule by incorporating variations in credit spreads and credit quantites. Teranishi [6] shows that the spreadadjusted Taylor rule (which includes a response to the

${ }^{*}$ corresponding author; e-mail: eepipien@cyf-kr.edu.pl credit spread) is a theoretically optimal monetary policy under heterogeneous loan contracts. In Del Negro et al. [7] the new Keynesian model with financial frictions was used to predict the recent word crisis of 2009 .

It should be noted that the business cycle is very well investigated. The classification of sources resulting with cyclical fluctuations is also known with respect to the length for more than a century. Economists identify the Kitchin cycle with the length 3 to 5 years, the Juglar investment cycle ( $7-11$ years), the Kuznets migration cycle (20-25 cycles) and the long-term cycle of 45 to 60 years (also called the Kondratiev wave) appeared due to the technological progress. It is obvious that the business fluctuations are observed in most free market economies. In the case of the financial fluctuations related to financial sector the problem is less explored and the fundamental problem may be the identification of financial cycle in a given economy.

Recently, a particular interest in empirical properties of the cyclical fluctuations of financial variables prompted new methodological studies resulting with more advanced techniques of modelling economic cycles. In particular, unobserved component model seems recently the most popular method to analyse univariate and multivariate dynamics of the business cycle. This approach initially proposed by Harvey and Trimbur [8] and Trimbur [9] was developed by Koopman and Shephard [10], and Pelagatti [11]. This approach is based on representing the component of cyclical fluctuations in terms of ARMA (or VARMA) model with multiple complex conjugate roots in AR polynomial. The idea of such model has also in- 
terpretation in terms of the spectral analysis. One of the crucial property of such approach is ability to present concentration of the mass of the spectral density function around frequency of interest. The multivariate setting was considered in Azevedo et al. [12] where the model with stationary multiple cyclical process with common frequency at each coordinate was examined. Harvey et al. [13] considered the trivariate example. One of the possible disadvantage of the underlined approach is that only a single frequency representing common fluctuations can be described.

There are several popular spectral measures used broadly in spectral analysis of the business cycle. The theoretical background concerning representation of cyclical fluctuations in terms of spectral characteristics can be found in Croux et al. [14], Hamilton [15], Priestley [16], and others. Empirical analyses on the basis of spectral measures were presented in Ftiti [17], Metz [18], Orlov [19, 20], Pakko [21], McAdam and Mestre [22], Uebele and Ritschl [23], and others. The main purpose of such approach is to obtain the cyclical pattern on the basis of nonparametric band-pass filters well known since the late 90's; see Hodrick and Prescott [24], Baxter and King [25], Christiano and Fitzgerald [26]. The advantages and disadvantages of such detrending procedure is subject of serious debate initiated by Canova [27] and Burnside [28]. In standard nonparametric spectral analysis the stationarity assumption plays a central role making consistent estimation of the spectral density possible. However, the estimates depends on so-called spectral window and length of the bandwidth; see Priestley [16], Žurbenko [29], Lenart [30].

In this paper we consider two alternative nonparametric approaches based on different but much more general assumptions compared to the examples of standard approach sketched above. The first approach is based on representing cyclical fluctuations in terms of almost periodic mean function utilising the idea of deterministic cycle; see Harvey [31], Lee [32], Lenart and Pipień [33-36]. From the definition, the almost periodically correlated (APC) time series may describe the irregular character of unconditional means for nonstationary time series. Provided the detrended time series follows almost periodicity in mean function, we relax the assumption of stationarity. Nonstationarity of the cycle component of the series, together with possible irregularities in the time pattern of the unconditional mean, makes our approach relatively flexible and much more general.

In this approach we apply a non-standard subsampling procedure to make formal statistical inference about the stylized facts of cycles observed in the aggregate time series. We show that the cyclical nature can be modelled in a flexible deterministic framework based on the mean function of the APC time series. The APC class is a generalization of the periodically correlated $(\mathrm{PC})$ class of time series, introduced by Gladyshev [37]. Periodically correlated time series generalise covariance stationary class of time series. The vast literature confirms the substantial empirical importance and flexibility of the PC and APC class, also called a class of cyclostationary processes in many time series applications, see: Parzen and Pagano [38], Osborn and Smith [39], Franses [40], Bollerslev and Ghysels [41], Franses and Boswijk [42], Burridge and Taylor [43], Lenart and Pipień [33, 44], Lenart [45], Lenart and Pipień [34], Lenart et al. [46], Mazur [47, 48], Lenart and Pipień [36]. For a review of existing literature see Napolitano [49]. According to Hurd and Miamee [50], the periodically correlated time series are nonstationary, where time varying unconditional expectation and autocovariance function exhibits regular periodic evolution in time domain. The generalization presented in Hurd [51, 52] and adopted in this paper assumes that the mean can be described by an almost periodic function.

The second approach is more popular and is based on detrending and nonparametric spectral analysis. However, the approach that we consider is not conventional since we are interested only in the concentration of the spectral mass. Consequently the estimation of the spectral density function on the whole interval is not necessary. At the first step to estimate the spectrum of the process related to cyclical fluctuations we use standard Hodrick and Prescot filtering procedure for different parameters of smoothness. The second step is not conventional. We use the natural interpretation of the spectral distribution function for filtered time series. Following by Croux et al. [14] we show that the allocation of the mass for spectral density function between two frequencies can be expressed in the terms of usual variance of the difference between filtered processes.

The stylized facts concerning credit cycle for developed economies are well-documented in paper of Claessens et al. [53], where seven developed countries was examined and in paper of Drehmann et al. [4], where 21 advanced OECD economies was examined. In Ref. [54] by Apostoaie and Percic, the relations between the business and credit cycles in 20 advanced and developing EU economies are examined. Gomez-Gonzalez et al. [55] applied the Granger-type causality tests are carried out in the frequency domain to analyse the relationship between financial and real business cycles for a sample of 33 countries.

The main empirical purpose of this paper is to characterize the credit and production cycle in selected developed and catching-up European economies. We analyse monthly series of the total credit and production. We make formal statistical inferences about the properties of the cycles. We discuss the empirical features of the cyclical components within the proposed methodology, and finally we extract them on the basis of the HP filter with an indirectly estimated smoothing parameter. The subsampling test of the significance of a particular frequency is used to make a comparative analysis of the properties of the credit cycle among the selected European countries. Section 2 contains research methodology, while in the main part of the paper - Sect. 3 - we present the empirical results. 


\section{Research methodology}

We develop two nonparametric approaches to test the empirical properties of the cyclical fluctuations in credit and production. The first one described in Sect. 2.1 is based on APC time series utilizing the idea of flexible Fourier form and subsampling procedure. The second approach described in Sect. 2.2 is based on spectral analysis provided the stationarity assumption of cyclical fluctuations. We contribute to the existing literature in both, theoretical and empirical, aspects. From theoretical viewpoint we develop methods of formal statistical inference about the main properties of elements of the financial cycle. The statistical uncertainty assessed within both approaches complements standard procedure applied in the macroprudential literature.

\subsection{Nonparametric flexible deterministic cycle model}

The standard approach in the analysis of cyclical fluctuations assumes that the observed time series $P_{t}$ can be decomposed to the trend, seasonal and cyclical patterns. As an example one may recall the unobserved component model proposed by Harvey et al. [13]. The most important cyclical component of analysed construct is stationary $\operatorname{ARMA}(2 n, 1)$ process $\psi_{n, t}$ with conjugate roots in AR part. In this approach, the trend component is an integrated random walk. Under appropriate assumptions the spectral density function of the cyclical component $\psi_{n, t}$ concentrate the mass close to unknown frequency $\lambda_{c}$, which corresponds to estimated length of the cycle (the higher value of $n$, the stronger concentration one may obtain). In this way the cyclical pattern has only a stochastic counterpart.

In this paper we propose an alternative approach, where the cyclical pattern is modelled in nonparametric way by parameters of almost periodic mean function. In our approach, we refer partially to standard decomposition of the observed series to trend and cyclical fluctuations. The latter component is described by an almost periodic function represented by a countable set of frequencies. This concept can be found in Lenart and Pipień [33, 34] and Lenart et al. [46].

Let us consider the natural logarithm of the observed real-valued time series, denoted by $\left\{P_{t}: t \in\right.$ $Z\}$. We assume that the unconditional expectation, denoted by $\mu_{P}(t)=E\left(P_{t}\right)$ for the process $\left\{P_{t}\right.$ : $t \in Z\}$ is represented by the sum of deterministic function $f(t, \beta)$ (polynomial of order $d$ ), parameterized by $\beta \in R^{d}$, and almost periodic function $g(t)$ of the form $g(t)=\sum_{\psi \in \Psi_{P}} m_{P}(\psi) \mathrm{e}^{\mathrm{i} \psi t}$ parameterized by unknown and finite set $\Psi_{P}=\{\psi \in[0,2 \pi)$ : $\left.\left|m_{P}(\psi)\right| \neq 0\right\}$ with corresponding Fourier coefficients: $m_{P}(\psi)=\lim _{n \rightarrow \infty}\left(\frac{1}{n} \sum_{t=1}^{n} g(t) \mathrm{e}^{-\mathrm{i} \psi t}\right)$. The function $g(t)$ can be written equivalently as

$$
g(t)=\sum_{\psi \in \Psi_{P} \cap[0, \pi]} a_{P}(\psi) \cos (\psi t)+b_{P}(\psi) \sin (\psi t) .
$$

Under these assumptions the unconditional expectation of the process $\left\{P_{t}: t \in Z\right\}$ is given by the formula

$$
\mu_{P}(t)=f(t, \beta)+\sum_{\psi \in \Psi_{P}} m_{P}(\psi) \mathrm{e}^{\mathrm{i} \psi t} .
$$

It should be emphasized that our inference is not based on second order properties (i.e., spectral density function). The cyclical properties of the observed time series are modelled using an almost periodic function that describes time changes of the unconditional mean. We assume that the data are observed $s$ times during a year. Let us consider $\Psi_{P}=\Psi_{P, 1} \cup \Psi_{P, 2} \cup \Psi_{P, 3}$ where $\Psi_{P, 1} \subset(0,2 \pi / 1.5 s)$ corresponds to cyclical fluctuations (each element $\psi \in \Psi_{P, 1}$ corresponds to the length of the cycle greater than 1.5 year and equal to $2 \pi / \psi$ ), $\Psi_{P, 2} \subset\{2 j \pi / s: j=0,1,2, \ldots, s-1\}$ contains frequencies corresponding to the seasonal pattern and $\Psi_{P, 3}$ contains remaining frequencies. For example the set $\Psi_{P, 3}$ may contain frequencies that corresponds to trading-day effects; see e.g. Ladiray [56], Lenart [57].

We use two popular filters, i.e. centered moving average $2 \times s M A$ and $d$-times differencing, to obtain the process $\tilde{P}_{t}=L_{d}(B) L_{2 \times s}(B) P_{t}$, where $L_{2 \times s}(B)=\left(B^{-s / 2}+\right.$ $\left.2 B^{-s / 2+1}+\ldots+2 B^{-1}+2+2 B+\ldots+2 B^{s / 2-1}+B^{s / 2}\right) /(2 s)$ and $L_{d}(B)=(1-B)^{d}, B^{i} X_{t}=X_{t-i}, i \in \mathbb{N}$. The process $\tilde{P}_{t}$ has the following property:

$$
E\left(\tilde{P}_{t}\right)=c+\sum_{\psi \in \Psi_{P, 1} \cup \Psi_{P, 3}} m_{\tilde{P}}(\psi) \mathrm{e}^{\mathrm{i} \psi t}
$$

where $m_{\tilde{P}}(\psi)=L_{d}\left(\mathrm{e}^{-\mathrm{i} \psi}\right) L_{2 \times s}\left(\mathrm{e}^{-\mathrm{i} \psi}\right) m_{p}(\psi)$ and $c$ denotes some constant; see Lenart and Pipien [33,34]. Consequently, the statistical inference about frequencies that corresponds to cyclical fluctuations (included in the set $\left.\Psi_{P, 1}\right)$ is performed without popular band-pass filtering procedures.

Lenart [45], Lenart and Pipień [33, 34, 44] and Lenart et al. [46] use a subsampling method to approximate the distribution of the test statistics involved with the following testing problem, formulated for any $\psi \in(0,2 \pi)$ :

$$
\begin{aligned}
& H_{0}: \psi \notin \Psi_{P}, \\
& H_{1}: \psi \in \Psi_{P} .
\end{aligned}
$$

The testing problem (3) is equivalent to

$$
\begin{aligned}
& H_{0}:\left|m_{\tilde{P}}(\psi)\right|=0 \\
& H_{1}:\left|m_{\tilde{P}}(\psi)\right| \neq 0 .
\end{aligned}
$$

The rejection of the null hypothesis in (4) is interpreted as the existence of the data support in favour of nonzero amplitude corresponding to a frequency $\psi \in(0,2 \pi)$ being tested. Such a frequency contributes as a cycle of a particular length in the observed deviations of the process $\left\{P_{t}: t \in \mathbb{Z}\right\}$ from the trend. The details of both the analytical form of the test statistics, the critical values of the proposed test as well as a discussion about the subsampling method's consistency can be found in Lenart [45] and Lenart and Pipień $[33,44]$. Note that test statistics and critical values are continuous functions of argument $\psi$. Therefore, in practice, the significance means that each frequency in some interval $\left(\psi_{n, \min } \psi_{n, \max }\right)$ exceeds the critical value. Assuming that we have only one significant frequency 
within such an interval, the natural estimator of this frequency proposed by Lenart [45] can be considered.

Note that $H_{1}$ hypothesis is not equivalent with the existence of the commonly understood business cycle. Burns and Mitchell (1946) claimed that:

\begin{abstract}
"Business cycles are a type of fluctuation found in the aggregate economic activity of nations that organize their work mainly in business enterprises: a cycle consists of expansions occurring at about the same time in many economic activities, followed by similarly general recessions, contractions, and revivals which merge into the expansion phase of the next cycle; this sequence of changes is recurrent but not periodic; in duration business cycles vary from more than one year to ten or twelve years; they are not divisible into shorter cycles of similar character with amplitudes approximating their own."
\end{abstract}

With the reference to the growth cycles Mintz (1972) claimed:

"Growth cycles are fluctuations in aggregate economic activity. A growth cycle consists of a period of relatively high growth rates occurring at about the same time in many economic activities, followed by a period of similarly widespread low growth rates which merges into the high-growth phase of the next cycle."

The reason is that aforementioned two concepts of cyclical fluctuations do not have a fully formal definition, and refer to unspecified aggregates and phenomena like phase and period without a strict definition. In practice, we analyse chosen aggregates in available time period and we identify model parameters with the cycle length (fluctuation period), amplitude of fluctuations or cycle phase. Therefore in practice the rejection $H_{0}$ means that a certain length of fluctuations (related to the frequency $\psi$ ) is significant from a statistical point of view in a given time window for analysed aggregate and under model assumptions. This does not guarantee repeatability of detected fluctuations in the future for this aggregate.

\subsection{Nonparametric approach within stationarity framework}

Each stationary time series $X_{t}$ with zero mean and autocovariance function $\gamma(\tau)$ is strongly harmonizable. In this case there exists a right continuous orthogonal increment process $Z(\lambda)$ such that $Z(-\pi)=0$ and $X_{t}=\int_{-\pi}^{\pi} \mathrm{e}^{\mathrm{i} t \lambda} \mathrm{d} Z(\lambda)$. Additionally, there exists a measure with bounded total variation (called: spectral distribution function) such that $\gamma(\tau)=\int_{-\pi}^{\pi} \mathrm{e}^{\mathrm{i} \tau \lambda} \mathrm{d} F(\lambda)$; see Brockwell and Davis [58], Loeve [59], Hurd and $\mathrm{Mi}-$ amee [50]. Let us consider a sequence of disjoint intervals
$A_{1} A_{2}, \ldots, A_{k}$ such that $[-\pi, \pi]=\bigcup_{j=1}^{k} A_{j}$. Then the autocovariance can be decomposed to obtain the following form:

$$
\gamma(\tau)=\sum_{j=1}^{k} \int_{A_{k}} \mathrm{e}^{\mathrm{i} \tau \lambda} \mathrm{d} F(\lambda),
$$

where $\int_{A_{k}} \mathrm{e}^{\mathrm{i} \tau \lambda} \mathrm{d} F(\lambda)$ can be interpreted as a influence of frequencies from interval $A_{j}$ to total variability of $\gamma(\tau)$. If measure $F$ is absolutely continuous with respect to the Lebesgue measure then exist a spectral density function $f(\cdot)$ such that $\gamma(\tau)=\int_{-\pi}^{\pi} \mathrm{e}^{\mathrm{i} \tau \lambda} f(\lambda) \mathrm{d} \lambda$. Note that the $F\left(\left[\lambda_{1} \lambda_{2}\right]\right)$ can be interpreted as a measure of total variation of the process corresponding to frequencies from interval $\left[\lambda_{1} \lambda_{2}\right]$. It can be expressed in a following way:

$$
\begin{aligned}
& F\left(\left[\lambda_{1}, \lambda_{2}\right]\right)=\frac{\lambda_{2}-\lambda_{1}}{2 \pi} \\
& \quad+\sum_{\tau \in \mathbb{Z} \backslash\{0\}} \frac{\mathrm{e}^{-\mathrm{i} \tau \lambda_{1}}-\mathrm{e}^{-\mathrm{i} \tau \lambda_{2}}}{2 \pi \mathrm{i} \tau} \gamma(\tau)=\int_{\lambda_{1}}^{\lambda_{2}} f(\lambda) \mathrm{d} \lambda ;
\end{aligned}
$$

see Theorem 4.9.1 in Brockwell and Davis [58] and Hurd and Miamee ([50], p. 163). The mass concentration of the spectral density function around some frequency means that these frequency is dominant when explaining cyclical properties of the process.

Suppose observe time series $X_{t}$ with the pseudospectrum $S_{X}(\cdot)$. The ideal one-sided linear filter $F_{\lambda}(\cdot)$ has the form

$$
F_{\lambda}(L)=\frac{\pi-\lambda}{\pi}-\sum_{k=1}^{\infty} \frac{\sin (k \lambda)}{k \pi}\left(L^{k}+L^{-k}\right) .
$$

This gives automatically the formula for two-sided ideal filter, i.e. $F_{\lambda_{1}}(L)-F_{\lambda_{2}}(L)$ where $\lambda_{1}<\lambda_{2} \in[0, \pi]$. According to standard spectral theory (see for example Brockwell and Davis [58] or Croux et al. [14] with application to business cycles) in case of filtered time series $F_{\lambda}(L)$ the pseudo spectral density function has the form $\left|F_{\lambda}(-\mathrm{i} \omega)\right|^{2} S_{X}(\omega)$. Hence the process $\left(F_{\lambda_{1}}(L)-\right.$ $\left.F_{\lambda_{2}}(L)\right) X_{t}$ has a nonzero pseudo spectral density only for arguments in the interval $\left[\lambda_{1} \lambda_{2}\right]$. Now let us consider hypothetical stationary process with such a truncated spectral density. If the interval $\left[\lambda_{1} \lambda_{2}\right]$ corresponds to frequencies of interest, then the problem of estimating the spectral density function seems crucial. Since

$$
\operatorname{var}\left(\left(F_{\lambda_{1}}(L)-F_{\lambda_{2}}(L)\right) X_{t}\right)=2 \int_{\lambda_{1}}^{\lambda_{2}} S_{X}(\omega) \mathrm{d} \omega,
$$

the higher variance $\operatorname{var}\left(\left(F_{\lambda_{1}}(L)-F_{\lambda_{2}}(L)\right) X_{t}\right)$ is considered the bigger mass concentration in the interval $\left[\lambda_{1}, \lambda_{2}\right]$ occur. Consequently the variance (6) can be interpret as a total cyclical variation in the interval $\left[\lambda_{1}, \lambda_{2}\right]$.

Since the ideal band-pass filter is a construct of an abstract nature, it is impossible in practice to concentrate spectral mass to a particular subset of frequencies. In this paper we use Hodrick and Prescott (HP) filter with usual variance estimator and numerical approximation 
to determine the estimates of the mass concentration under pseudo-spectral density function based on (6). Let $H P_{\lambda}(L)$ denote the HP filter. In this case we rewrite analogous of the formula (6) via

$$
\begin{aligned}
& \operatorname{var}\left(\left(H P_{\lambda_{1}}(L)-H P_{\lambda_{2}}(L)\right) X_{t}\right)= \\
& \quad 2 \int_{0}^{\pi}\left|H P_{\lambda_{1}}(L)-H P_{\lambda_{2}}(L)\right|^{2} S_{X}(\omega) \mathrm{d} \omega .
\end{aligned}
$$

The right side of (7) is interpreted as an approximation of mass concentration under pseudo-spectral density function in the interval $\left[\lambda_{1}, \lambda_{2}\right]$.

Let us denote by $\boldsymbol{X}_{n}=\left[X_{1}, X_{2}, \ldots, X_{n}\right]^{\prime}$ the vector of observation. For any fixed $\lambda$ we denote by $\boldsymbol{\psi}_{n}(\lambda)=$ $\left[\psi_{1}(\lambda), \psi_{2}(\lambda), \ldots, \psi_{n}(\lambda)\right]^{\prime}$ the random element which is a cycle component in HP filtering procedure. More precisely using matrix notation

$$
\boldsymbol{\psi}_{n}(\lambda)=\left(I-(I+\lambda A)^{-1}\right) \boldsymbol{X}_{n},
$$

where the matrix $A=\left[a_{i j}\right]_{n \times n}$ is a symmetric real valued matrix with the following elements:

$$
a_{i j}=\left\{\begin{aligned}
6 & \text { for } i=j \text { and } i=3,4, \ldots, n-2, \\
-4 & \text { for }|i-j|=1 \text { and } i=2,3, \ldots, n-1, \\
1 & \text { for }|i-j|=2 \text { and } i=1,2, \ldots, n, \\
5 & \text { for } i=j=2, \\
-2 & \text { for }|i-j|=1 \text { and } i \in\{1, n\}, \\
1 & \text { for } i=j \text { and } i \in\{1, n\} .
\end{aligned}\right.
$$

For any interval $\left[\lambda_{1}, \lambda_{2}\right]$ we estimate the parameter $\operatorname{var}\left(\left(H P_{\lambda_{1}}(L)-H P_{\lambda_{2}}(L)\right) X_{t}\right)$ by sample variance estimator based on sample $\boldsymbol{\psi}_{n}\left(\lambda_{1}\right)-\boldsymbol{\psi}_{n}\left(\lambda_{2}\right)$.

In this approach it is assumed the stationarity of cyclical fluctuations and their zero expected value in contrast to the methodology presented in the previous subsection. From a practical point of view, the higher $\operatorname{var}\left(\left(H P_{\lambda_{1}}(L)-H P_{\lambda_{2}}(L)\right) X_{t}\right)$ values on obtains, the higher proportion of fluctuations with a length is corresponding to the frequency in the interval $\left[\lambda_{1}, \lambda_{2}\right]$.

\section{Empirical results}

We analysed monthly time series of the credit and production aggregates in 18 selected European countries, namely Belgium, Czech Republic, Germany, Estonia, Greece, Spain, France, Italy, Lithuania, Hungary, Netherlands, Poland, Portugal, Romania, Slovakia, Finland, Sweden and United Kingdom. Note that some of them are well developed economies while some belongs to Central or Eastern Europe catching-up economies. The series of production were taken from Eurostat, while the credit series were obtained from national statistical offices or European Central Bank. The credit aggregate informs about the total credit issued to nonfinancial institution (firms and households) by banks. It was expressed in EUR currency for each country. Nominal effects were adjusted by HICP inflation. Table I presents number of observations in both cases. The last observation in each country concerns December 2015. The shortest series subject to modelling was considered in case of credit aggregate in Slovakia (120 observations).

TABLE I

The length of observed monthly time series of the credit aggregate and production. Each dataset ends at December 2015 .

\begin{tabular}{l|c|c}
\hline \hline \multicolumn{1}{c|}{ Country } & Credit & Production \\
\hline Belgium & 204 & 192 \\
Czech Republic & 168 & 192 \\
Germany & 204 & 252 \\
Estonia & 228 & 192 \\
Greece & 252 & 192 \\
Spain & 252 & 252 \\
France & 252 & 252 \\
Italy & 211 & 252 \\
Lithuania & 139 & 216 \\
Hungary & 192 & 192 \\
Netherlands & 156 & 192 \\
Poland & 204 & 192 \\
Portugal & 156 & 192 \\
Romania & 133 & 192 \\
Slovakia & 120 & 192 \\
Finland & 156 & 252 \\
Sweden & 204 & 192 \\
United Kingdom & 204 & 216
\end{tabular}

Figure 1 and 2 show how the value of the test statistics (solid line) used in the testing procedure (4) changes with respect to the frequency. The dashed lines present the subsampling critical values calculated at significance levels of $0.08,0.05$ and 0.02 . In Fig. 1 we put the results for the credit time series, while in Fig. 2 we present analogous results for the monthly series of industrial production in the analysed countries. Changes in the test statistics' values are irregular, making inference about empirical importance of a particular frequency very difficult. Standard, qualitative analysis that relies on the frequencies with dominant amplitude is ad hoc and leaves doubts about the nature of cyclical changes supported by the observed series. However, the test statistics indicate rejection of the null hypothesis in (4) only for a few values of frequency. In general, the credit cycles in the analysed countries can be described by a cyclical component with a longer period than in the case of production, as the test statistics are greater than the critical values for frequencies much lower than those obtained for series of industrial production.

The length of cycles (in years) corresponding to statistically significant frequencies at significance level $\alpha=$ 0.02 , according to the testing procedure (4) are presented in Tables II and III. Again, we compare the properties of the credit cycle with those describing the production cycle. The results confirm the diversity of the cyclical components across the analysed countries. However, the data indicate the existence of much longer cyclical 
TABLE II

Credit cycle: estimated length of cycles (in years) corresponding to statistically significant frequencies (at significance level $\alpha=0.02$ ), according to the testing procedure (4). Lower and upper bound corresponds to interval with statistically significant frequencies that contains one point estimate (at significance level $\alpha=0.02$ ).

\begin{tabular}{|c|c|c|c|}
\hline Country & Lower bound & Upper bound & $\begin{array}{l}\text { Point estimate } \\
\text { of cycle length }\end{array}$ \\
\hline \multirow[t]{4}{*}{ Belgium } & 9.26 & 16.67 & 12.82 \\
\hline & 2.65 & 2.73 & 2.72 \\
\hline & 1.98 & 2.01 & 2.00 \\
\hline & 1.74 & 1.75 & 1.74 \\
\hline Czech Rep. & 8.77 & 20.83 & 12.82 \\
\hline \multirow[t]{3}{*}{ Estonia } & 9.26 & 23.81 & 13.89 \\
\hline & 2.53 & 2.60 & 2.59 \\
\hline & 1.96 & 2.11 & 2.03 \\
\hline \multirow[t]{5}{*}{ Germany } & 7.25 & 11.11 & 8.77 \\
\hline & 5.21 & 5.38 & 5.32 \\
\hline & 3.55 & 4.07 & 3.79 \\
\hline & 2.82 & 3.14 & 2.98 \\
\hline & 2.08 & 2.11 & 2.09 \\
\hline \multirow[t]{2}{*}{ Greece } & 16.67 & 41.67 & 27.78 \\
\hline & 2.45 & 2.56 & 2.53 \\
\hline Spain & 13.89 & 41.67 & 23.81 \\
\hline \multirow[t]{2}{*}{ France } & 16.67 & 18.52 & 18.00 \\
\hline & 5.56 & 8.33 & 7.58 \\
\hline Italy & 16.67 & 33.33 & 23.81 \\
\hline Lithuania & 5.38 & 23.81 & 13.89 \\
\hline \multirow[t]{2}{*}{ Hungary } & 8.33 & 55.56 & 20.83 \\
\hline & 2.87 & 3.27 & 3.09 \\
\hline \multirow[t]{2}{*}{ Netherlands } & 10.42 & 33.33 & 16.67 \\
\hline & 3.21 & 3.97 & 3.55 \\
\hline \multirow[t]{2}{*}{ Poland } & 5.56 & 10.42 & 7.25 \\
\hline & 3.55 & 3.62 & 3.60 \\
\hline \multirow[t]{2}{*}{ Portugal } & 8.77 & 41.67 & 15.15 \\
\hline & 2.38 & 2.65 & 2.53 \\
\hline \multirow[t]{2}{*}{ Romania } & 9.26 & 23.81 & 13.89 \\
\hline & 4.76 & 5.21 & 5.01 \\
\hline \multirow[t]{2}{*}{ Slovakia } & 7.94 & 16.67 & 11.90 \\
\hline & 3.33 & 4.39 & 4.07 \\
\hline \multirow[t]{2}{*}{ Finland } & 9.80 & 41.67 & 16.67 \\
\hline & 3.88 & 4.27 & 3.97 \\
\hline \multirow[t]{3}{*}{ Sweden } & 10.42 & 18.52 & 13.89 \\
\hline & 4.07 & 4.50 & 4.27 \\
\hline & 2.49 & 2.73 & 2.60 \\
\hline \multirow[t]{5}{*}{ UK } & 12.82 & 41.67 & 20.83 \\
\hline & 4.90 & 8.33 & 7.94 \\
\hline & 2.49 & 2.53 & 2.50 \\
\hline & 2.01 & 2.08 & 2.06 \\
\hline & 1.62 & 1.76 & 1.68 \\
\hline
\end{tabular}

${ }^{a}$ (transformed frequency estimate)

components for the credit aggregate compared to the production fluctuations. The predominant values of the test statistics is concentrated around frequencies that correspond to cycle of length approximately 8-10 years, while for production cycle the mass is concentrated mainly in the range of so-called Kitchin cycle (2-4 years). Only in the case of Germany, Poland, and Sweden the predominant value of test statistics for credit cycle is concentrated around frequencies that correspond to relatively shorter cycle. The cyclical nature is also in general supported strongly for credit, where for each country some cyclical components are identified. Under reasonable significance level one may find countries with no significant cyclical component in production series; see Table III, the case of France, Italy, Estonia, Germany, and Hungary. The nature of cyclical fluctuations in such countries is not enough regular to be recognized (using presented test) as the linear combination of the sine and cosine deterministic functions. On the other hand, the heuristic analysis of the periodogram for these countries clearly indicate that the Kitchin cycle is predominant in cyclical fluctuations of production in these countries. But our subsampling scheme indicates that it is insignificant from the view of the data.

TABLE III

Production cycle: estimated length of cycles (in years) corresponding to statistically significant frequencies (at significance level $\alpha=0.02$ ), according to the testing procedure (4). Lower and upper bound corresponds to interval with statistically significant frequencies that contains one point estimate (at significance level $\alpha=0.02$ ).

\begin{tabular}{|c|c|c|c|}
\hline Country & Lower bound & Upper bound & $\begin{array}{l}\text { Point estimate } \\
\text { of cycle length }\end{array}$ \\
\hline \multirow[t]{2}{*}{ Belgium } & 16.67 & 23.81 & 18.52 \\
\hline & 2.98 & 3.47 & 3.21 \\
\hline Czech Rep. & 3.21 & 3.70 & 3.47 \\
\hline Estonia & - & - & - \\
\hline Germany & - & - & - \\
\hline Greece & 8.77 & 15.15 & 11.90 \\
\hline Spain & 18.52 & 23.81 & 20.83 \\
\hline France & - & - & - \\
\hline Italy & - & - & - \\
\hline \multirow[t]{4}{*}{ Lithuania } & 7.25 & 15.15 & 9.80 \\
\hline & 4.76 & 4.90 & 4.80 \\
\hline & 3.14 & 3.33 & 3.27 \\
\hline & 2.25 & 2.56 & 2.42 \\
\hline Hungary & - & - & - \\
\hline \multirow[t]{2}{*}{ Netherlands } & 16.67 & 23.81 & 20.83 \\
\hline & 2.78 & 3.14 & 2.92 \\
\hline \multirow[t]{4}{*}{ Poland } & 12.82 & 13.89 & 13.20 \\
\hline & 5.95 & 7.58 & 6.41 \\
\hline & 3.14 & 4.07 & 3.55 \\
\hline & 1.81 & 1.98 & 1.92 \\
\hline Portugal & 3.21 & 4.90 & 4.17 \\
\hline \multirow[t]{3}{*}{ Romania } & 5.56 & 7.94 & 6.41 \\
\hline & 3.14 & 3.70 & 3.40 \\
\hline & 1.67 & 1.83 & 1.77 \\
\hline Slovakia & 3.62 & 4.39 & 3.97 \\
\hline \multirow[t]{2}{*}{ Finland } & 20.83 & 41.67 & 27.78 \\
\hline & 1.87 & 2.03 & 1.96 \\
\hline UK & 3.40 & 3.79 & 3.62 \\
\hline
\end{tabular}

${ }^{a}$ (transformed frequency estimate) 
Belgium

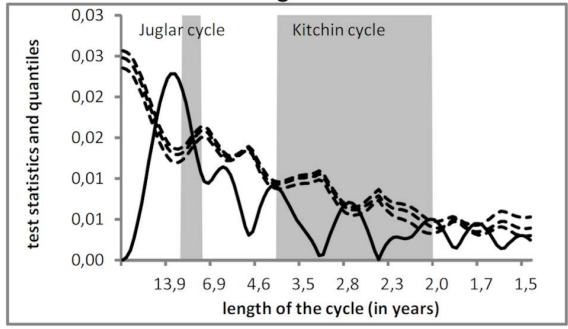

Estonia

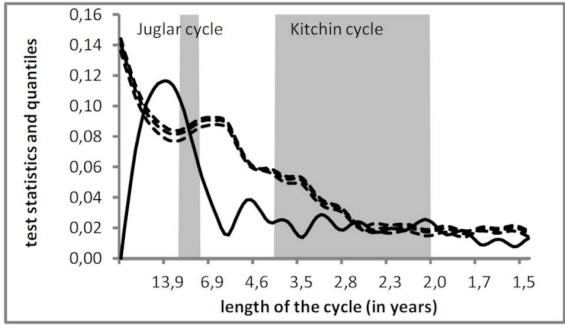

France

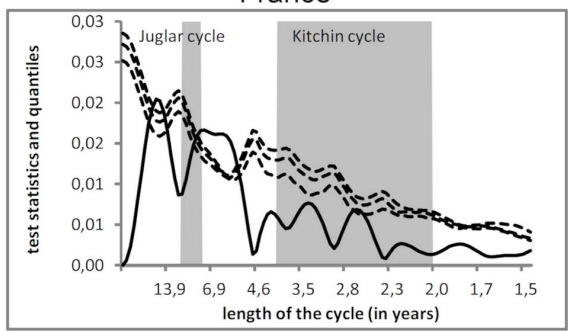

Hungary

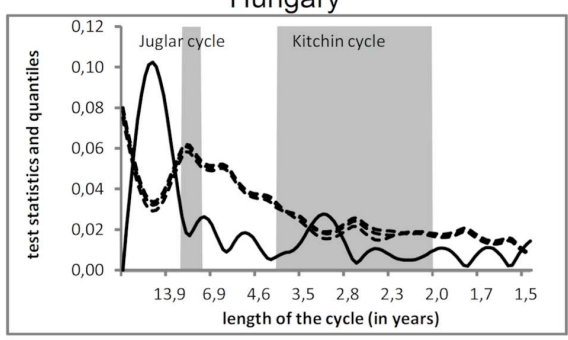

Portugal

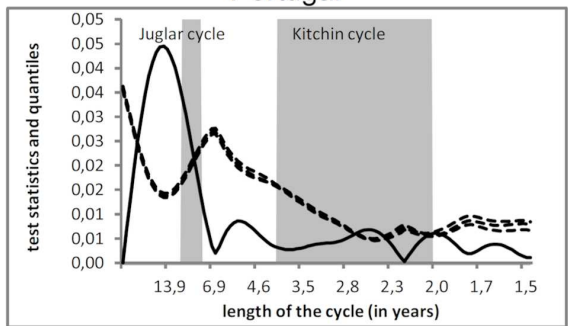

Finland

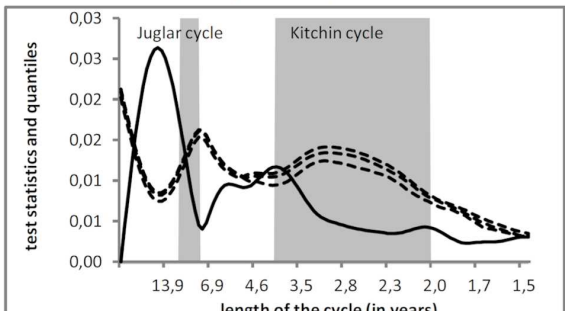

length of the cycle (in years)
Czech Republic

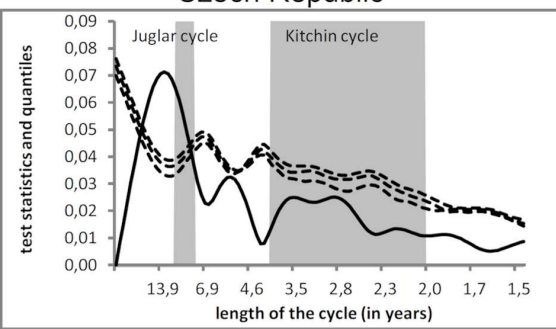

Greece

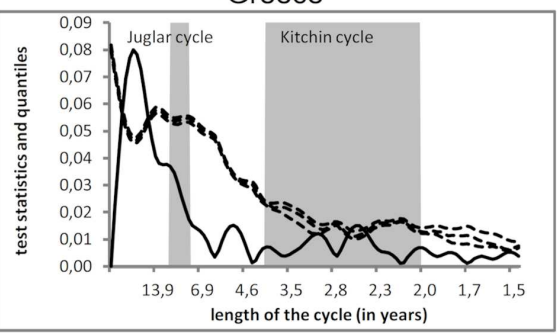

Italy

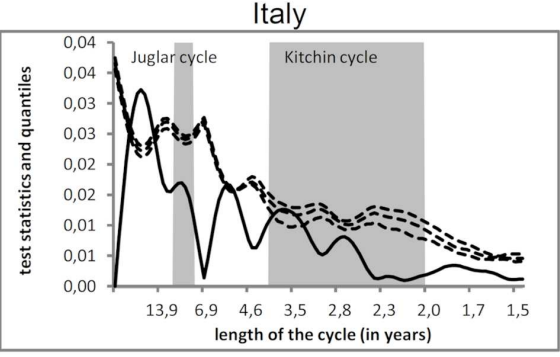

Netherlands

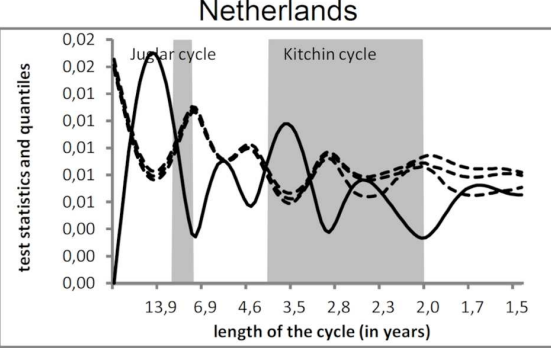

Romania

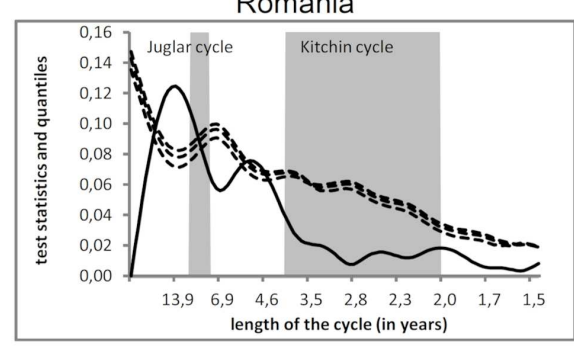

Sweden

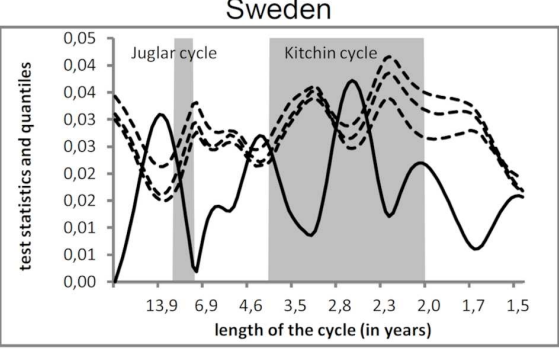

Germany

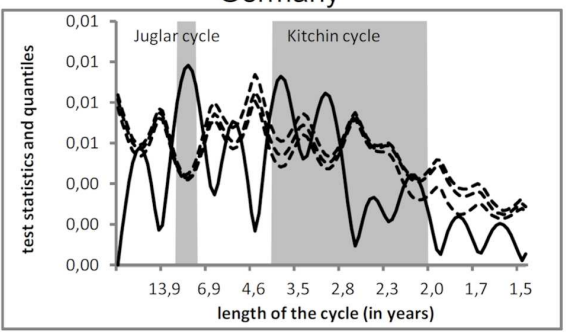

Spain

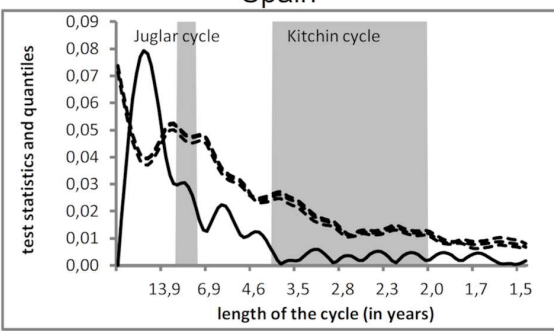

Lithuania

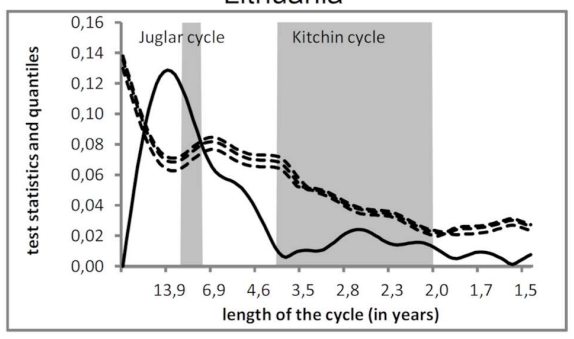

Poland

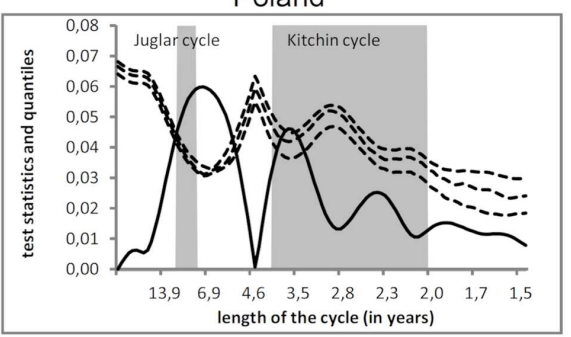

Slovakia

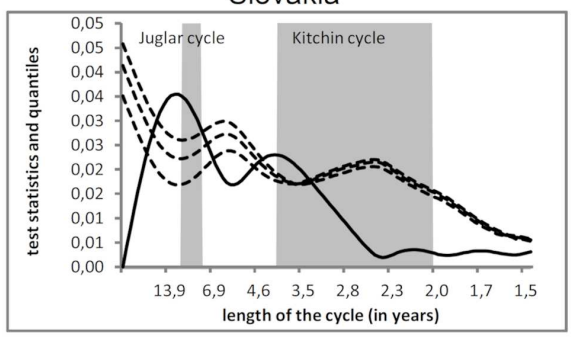

United Kingdom

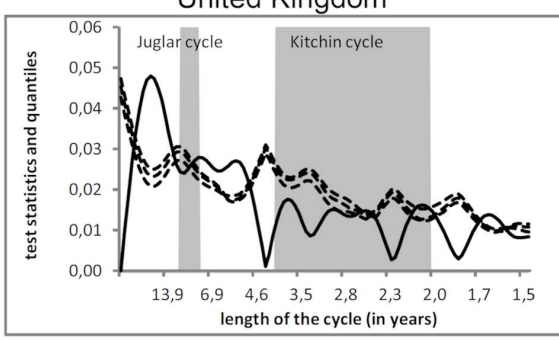

Fig. 1. Credit cycle: the test statistics (solid line) and subsampling critical values (dashed lines) at the significance levels $\alpha=0.08,0.05$, and 0.02 utilized in testing scheme (4). 

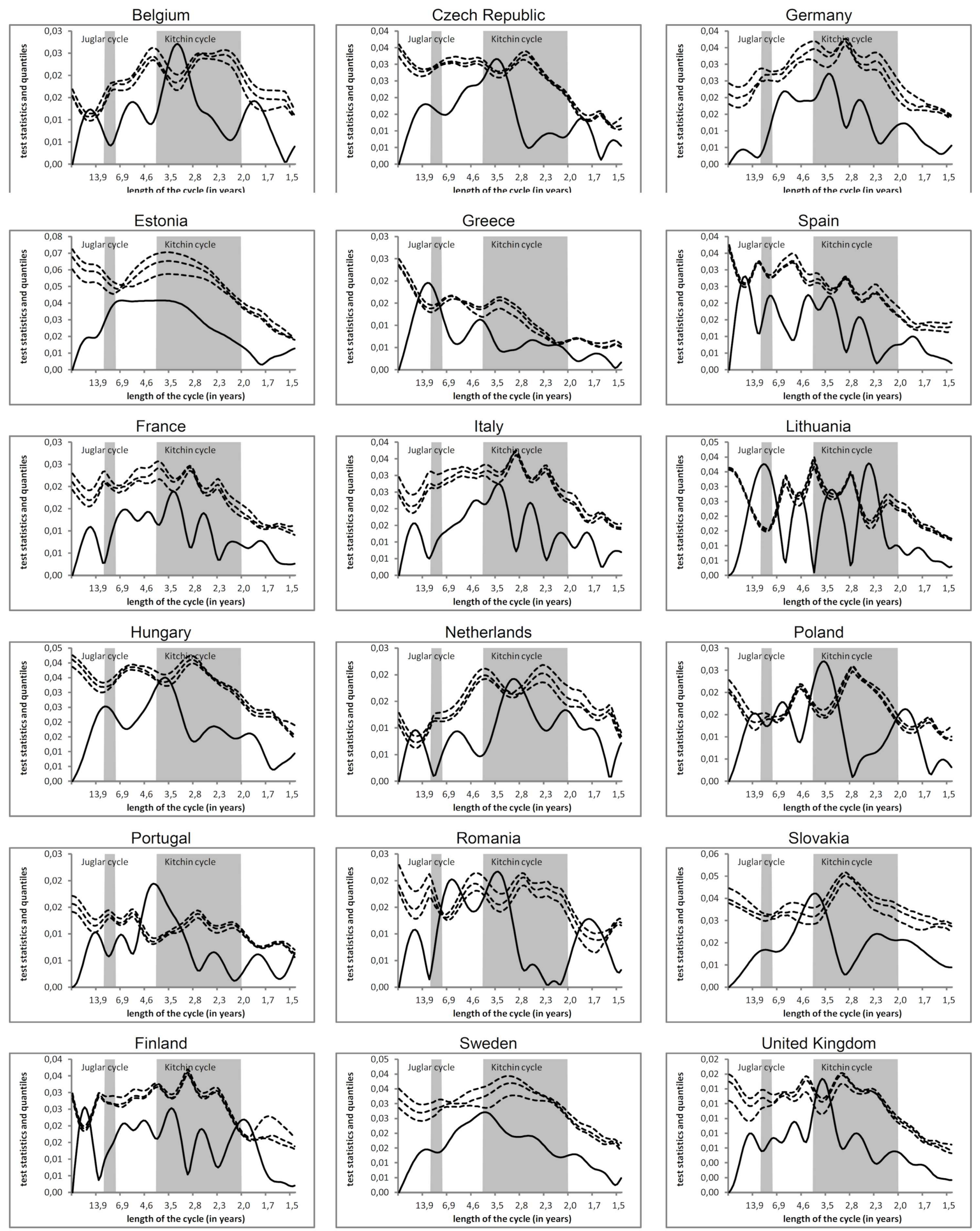

Fig. 2. Production cycle: the test statistics (solid line) and subsampling critical values (dashed lines) at the significance levels $\alpha=0.08,0.05$, and 0.02 utilized in testing scheme (4). 
The analysis discussed above shows serious problems in establishing the reference value of the period of the credit cycle, and, in general, the financial cycle. The empirical analyses show clearly that even among countries of relatively comparable size and level of development, the cyclical components may be different. Additionally, in predominant cases statistically significant frequencies support the length of a cycle much shorter than the reference values discussed in the literature; see Borio [60] and Drehmann [4].

Next we extract the cyclical components from the analysed monthly series and present it in Fig. 3 (credit) and Fig. 4 (production). The extraction procedure is based on the HP filter with a smoothing parameter corresponding to the frequency of a period of 5 years (solid line) and 10,15 , and 20 years (appropriate dashed lines). For predominant cases we see regular cyclical changes and clear indication of expansion and contraction phases. The amplitude of the credit cycle, as measured by the percentage of maximum deviations from the long-term trend, is not precisely identified and exhibits substantial variability with respect to changes in the smoothing parameter in the HP filter.

In particular, two expansion phases of credit that occurred in Poland in 2001 and 2009 can be described by positive deviation from the trend, reaching values from $2 \%$ (HP parameter set to 5 years) to $20 \%$ (HP parameter set to 20 years). Additionally, during the expansion in Poland in 2009, the deviation from the trend differs and can reach the value $5 \%$ (HP parameter set to 5 years) or $20 \%$ (HP parameter set to 20 years). The scale of the credit expansion in the Czech Republic during 2008-2009 is also sensitive with respect to the smoothing parameter. The peak at the end of 2009 is described by deviation from the trend from $3 \%$ (HP parameter set to 5 years) to $18 \%$ (HP parameter set to 20 years). In addition to the irregular shape of the cyclical component for credit in Hungary, its deviation from the long-term trend is also very sensitive with respect to the smoothing parameter. Like in Poland and the Czech Republic, the picture of the credit expansion during 2008-2009 is vague because the peak may reach values smaller than $3 \%$ (HP parameter set to 5 years) or greater that $20 \%$ (HP parameter set to 20 years).

Analysing contraction phases in the credit leads to the same conclusions for all countries. In Poland, the negative deviation from the long term trend in 2005-2006 may reach values from $2.5 \%$ (HP parameter set to 5 years) to $19 \%$ (HP parameter set to 20 years). Additionally, in 2014 , the deviation from the cycle may differ in a comparable way. The extracted cyclical components in all analysed countries, provided the smoothing parameter is set to 5 years, makes difficult to distinguish regular changes in phases. The peaks and troughs are not strongly identified. Phases of the analysed cycles, peaks and troughs are barely localized if the smoothing parameter correspond up to 10 years. The picture of the cyclical changes in the credit growth becomes clearer, as the HP filter strengthens much longer periods and weakens those of periods shorter than 10 years. This shows that the inference about significant frequencies discussed above (see Figs. 1 and 2 and Tables II and III) is crucial for appropriate choice of filtration parameter.

The results discussed above were obtained on the basis of the deterministic framework that the cycle can be obtained on the basis of the process with almost periodic fluctuations in mean function. We confront those results with the stochastic framework. Figures 5 and 6 present the concentration of the mass of the pseudo spectral density in case of credit (Fig. 5) and production (Fig. 6) in each analysed country. Presented plots are normalised to the scale from $0 \%$ to $100 \%$ and show the concentration of mass attached to particular set of frequencies. We split the whole analysed spectrum into four sets, namely the set of frequencies corresponding to short cycles (1.55 years), medium cycles (5-10 years), long cycles (10-15 years) and very long cycles (15-20 years). The distribution of the spectrum mass is clearly different in case of the credit compared as compared to the production. The credit time series support substantial concentration of the spectrum mass around frequencies corresponding to long cycles, while in case of production frequencies correspond to cycles not longer than a decade cumulate at least $75 \%$ of the mass. Short term cycles (1.5 to 5 years) are improbable in the view of the credit series in case of Belgium, Estonia, Greece, Spain, Lithuania, Portugal, and Romania. Majority of countries support existence of very long cycles (15-20 years), except Germany, Poland, and Slovakia.

The identification of cycles with the length more than 10 years means that we cannot observe their repeatability in the analyzed data. Hence the identified fluctuations longer than 10 years have not been forced by shocks and impulses, such as the recent world crisis or EU funds. Therefore, in the next part, we will attempt to analyze the dependence of the production cycle with credit fluctuations more closely. We perform standard correlation analysis between cyclical components in credit across analysed countries for different smoothness parameters in HP filtration. The results are presented in Tables IVVII (values below main diagonal). The same analysis is available for production cycle (see values above main diagonal in Tables IV-VII). Production cycles seem more synchronized across analysed countries than credit cycles as the sample correlation in case of production cycles is relatively higher than in case of credit. In case of production cycle the higher values of sample correlations are obtained provided the smoothness parameter corresponding to 5 years. For 10,15 , and 20 years the sample correlations have tendency to decrease. This suggests that the most similar fluctuations in credit and production are of up to 5 years, which are predominant in production cycle (see Fig. 6). In case of credit cycle the higher sample correlation coefficients are obtained mainly for the smoothness parameter that corresponds to a much longer cycle (20 years). 
1380
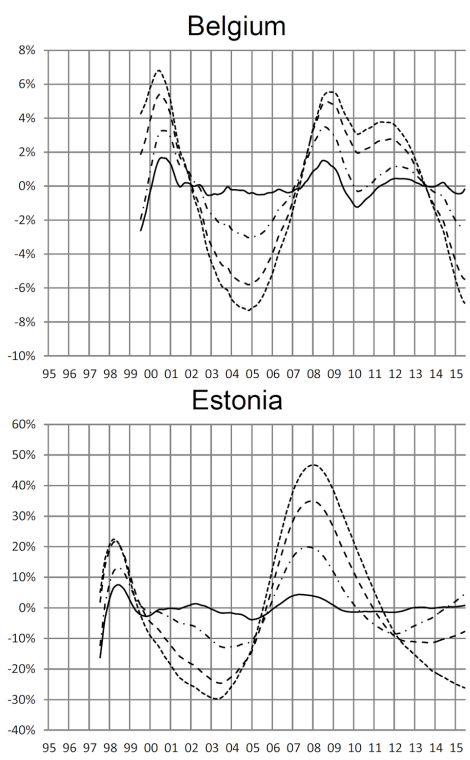

France
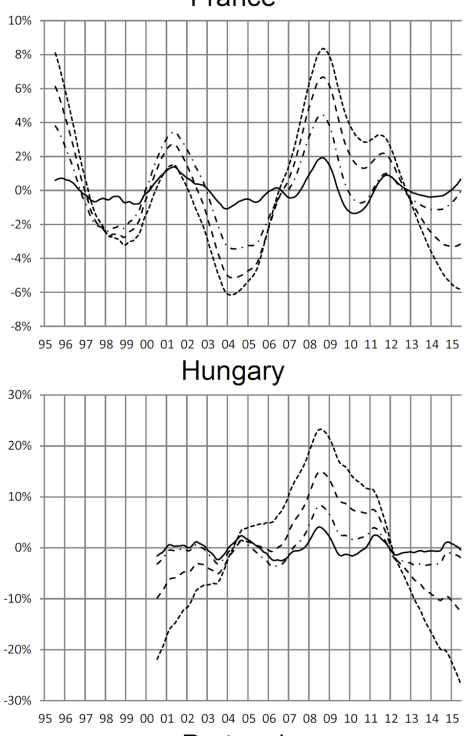

Portugal
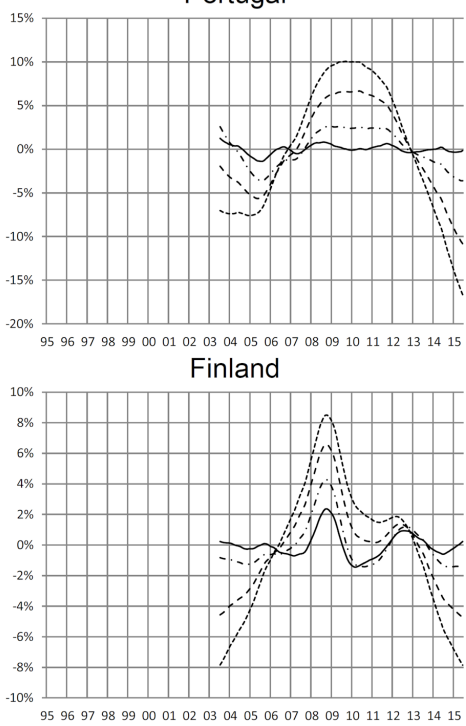

E. Lenart, M. Pipień

Czech Republic
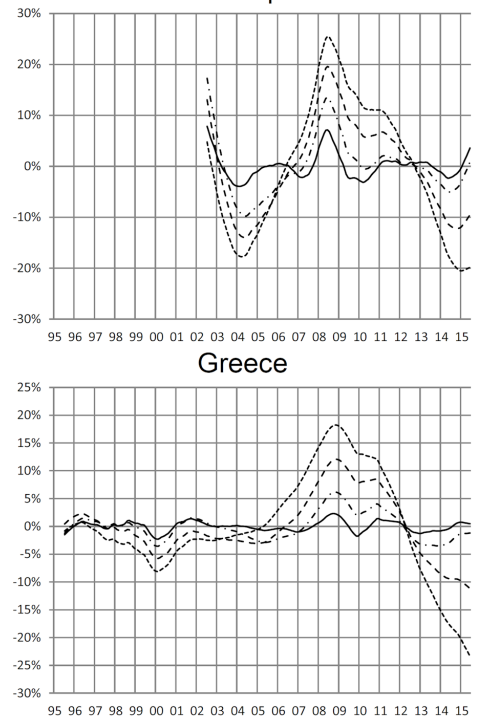

Italy

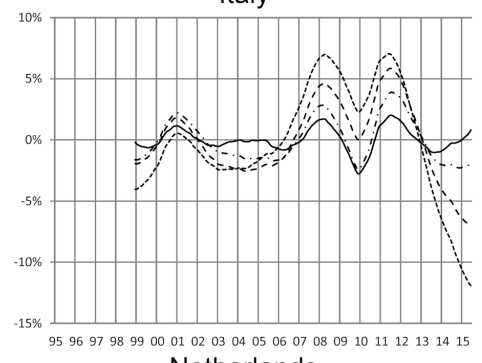
Netherlands

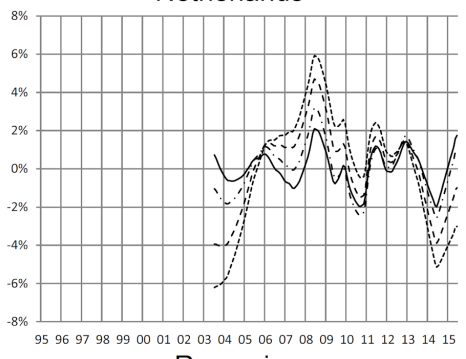

Romania
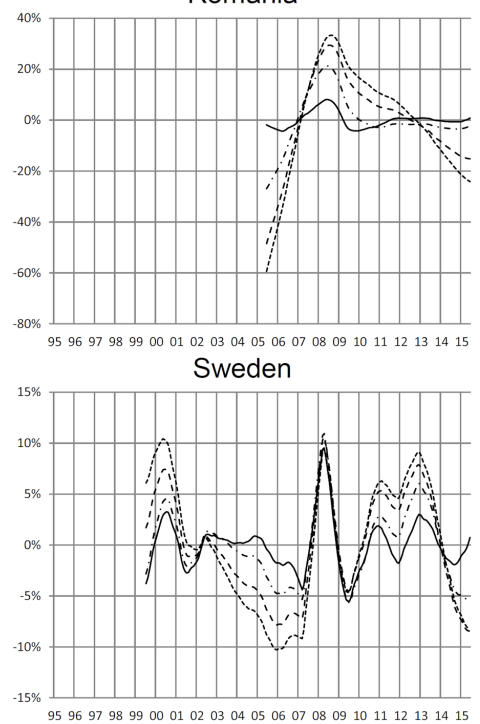

Germany
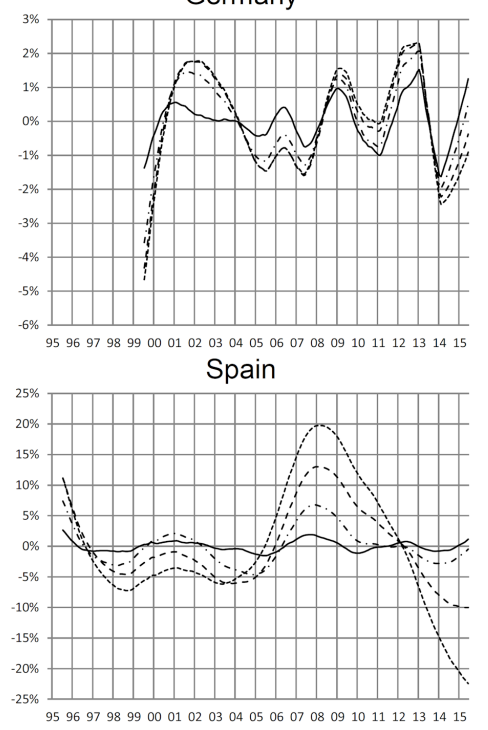

Lithuania

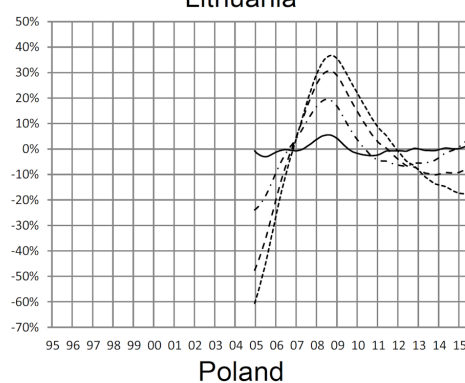

Poland

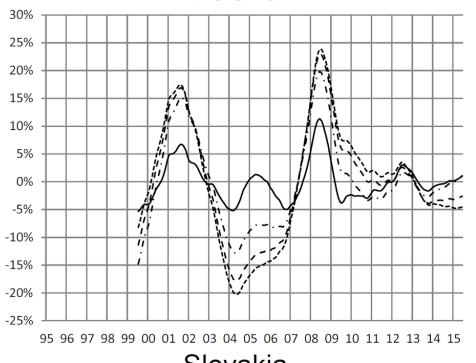

Slovakia
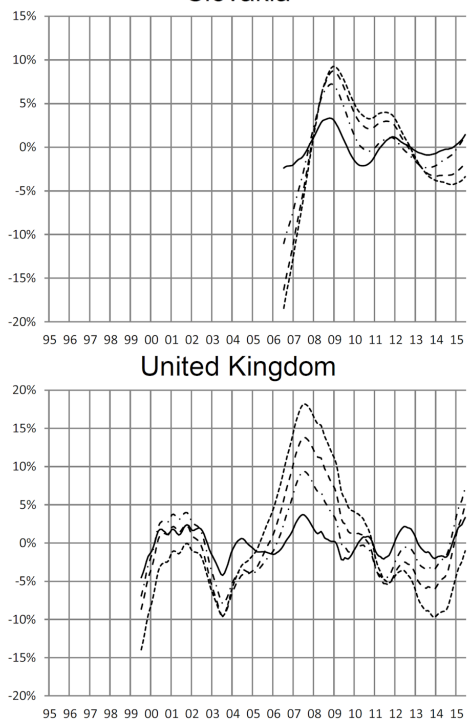

Fig. 3. Cyclical components extracted on the basis of HP filter with smoothing parameter $\lambda$ corresponding to length of cycle: 5 years (solid line); 10 years $(-\cdot-\cdot-\cdot-), 15$ years $(----)$, and 20 years $(------)$ for credit. 
Cyclical Properties of the Credit and Production in Selected European Countries...

Belgium

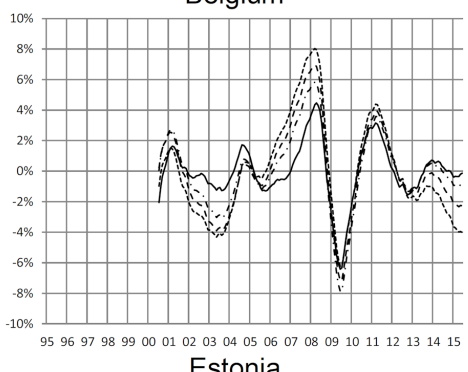

Estonia

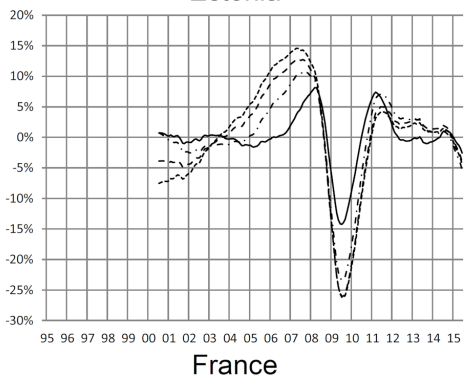

France
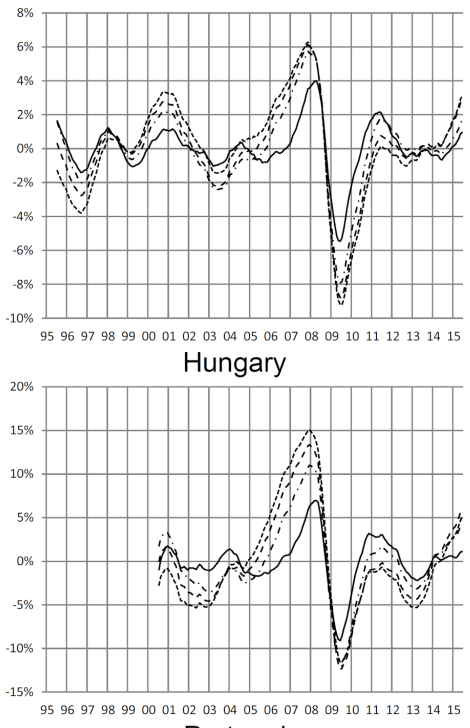

Portugal
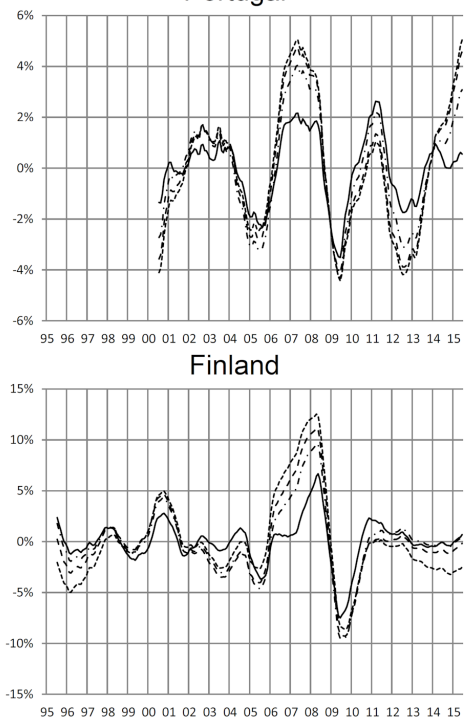

Czech Republic
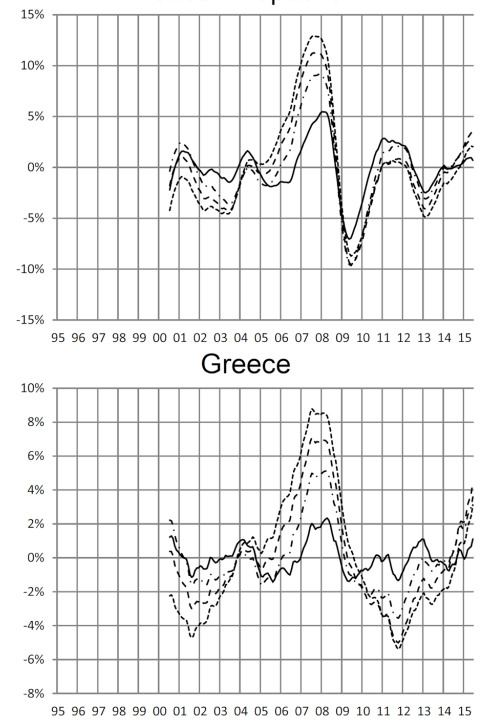

Italy

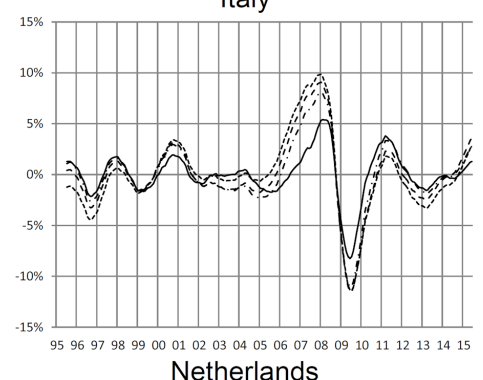

Netherlands

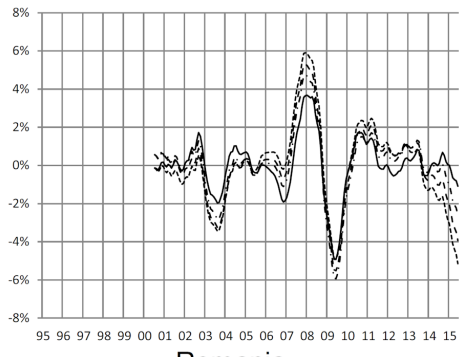

Romania
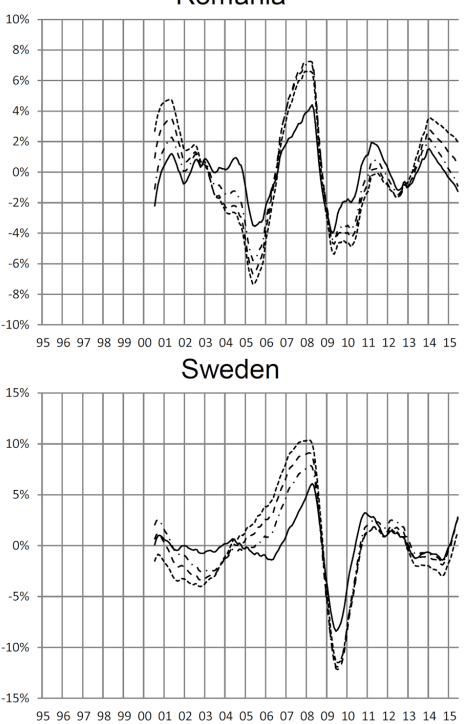

Germany
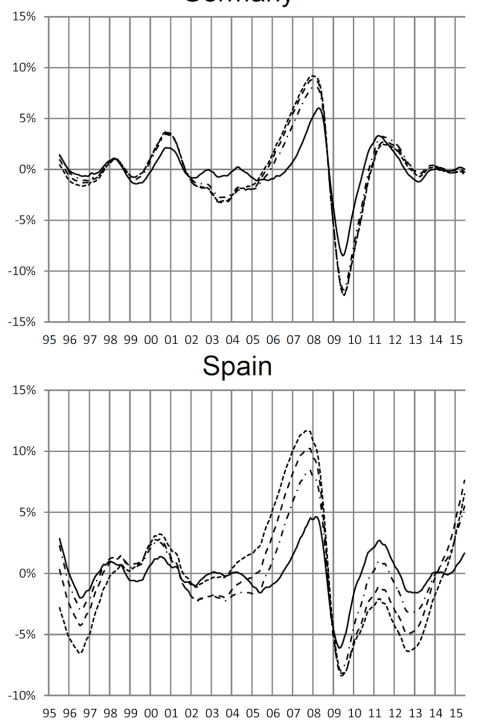

Lithuania
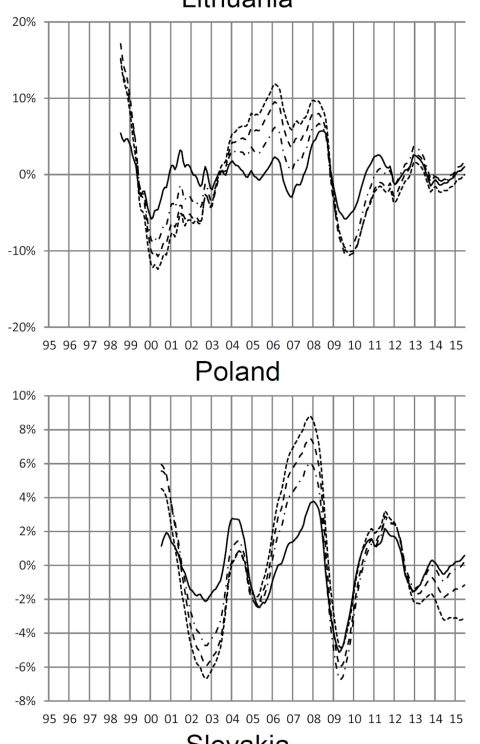

Slovakia
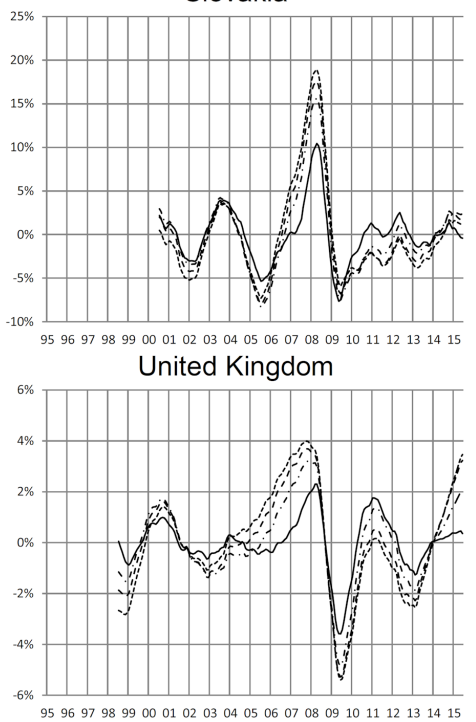

Fig. 4. Cyclical components extracted on the basis of HP filter with smoothing parameter $\lambda$ corresponding to length of cycle: 5 years (solid line); 10 years $(-\cdot-\cdot-\cdot-)$, 15 years $(----)$, and 20 years $(------)$ for production. 


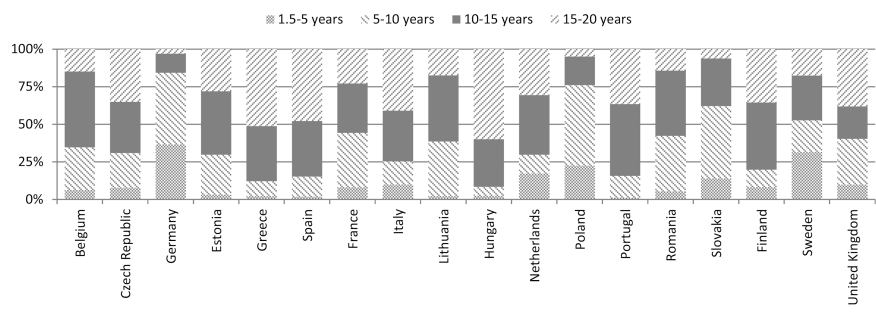

Fig. 5. Estimated mass concentration for pseudo spectral density; the case of credit. Frequency corresponds to length from 1.5 to 20 years.

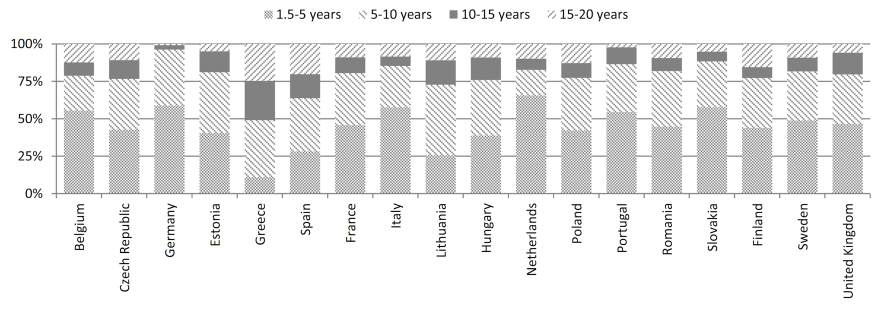

Fig. 6. As in Fig. 5, but for the case of production.

For qualitative analysis of dynamic dependence between production and credit cycle we performed standard lead-lag analysis. In Table VIII we present sample correlation coefficients $\operatorname{Corr}\left(C_{t}, P_{t+n}\right)$ between current value of the credit cycle $C_{t}$ and shifted value of the production cycle $P_{t+n}$, for $n=0, \pm 1, \pm 2, \ldots, \pm 8$. The results were obtained in four cases of the smoothing parameter corresponding to 5, 10, 15, and 20 years, respectively. Positive sample correlations for negative $n$ in each country except Lithuania indicate that the credit cycle precedes production cycle. This result could be particularly useful when building theoretical model of interactions between real sector of economy and the financial system. Motivating the substantial role of the financial sector Minsky [61] claimed that the production obviously precedes exchange of goods and production factors. But also there is no doubt that finance precedes production due to allocation process and necessary purchase of production factors. Our empirical findings confirm Minsky hypothesis at least in case of the set of analysed countries. The results that the credit cycle precedes production cycle seems invariant with respect to the value of the smoothing parameter, however in case of much longer cycles the relationship between current value of the credit cycle and lagged value of the production cycle is stronger. For Sweden, Germany and France this relationship is very weak. The strongest effect was obtained for the Netherlands, Finland, UK, and Greece. In those cases the correlation $\operatorname{Corr}\left(C_{t}, P_{t-8}\right)$ reaches value 0.6.

The analysed period covered many unexpected shocks. The most important of them is the global financial crisis which occurred in 2008. This crisis was reflected in the dynamics and features of both the credit and production cycles. A strong increase in the amplitude of the production cycle is clearly visible in almost all European economies. For example, the great crisis for the Greek economy played a significant role in the dynamics of the cycle. One should also take into account the huge EU funds received by the European economies, which were likely to have a significant impact on the dynamics of both the credit and production cycles. However it is not easy to separate the impact of the recent world crisis and EU funds on the dynamics of the cycle, because econometrics has not developed so far in this direction.

Sample correlations between production cycles (above main diagonal) and credit cycles (below main diagonal). Smoothing parameter $\lambda$ corresponds to 5 years.

\begin{tabular}{|c|c|c|c|c|c|c|c|c|c|c|c|c|c|c|c|c|c|c|}
\hline & 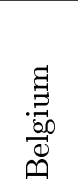 & 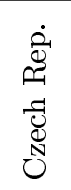 & 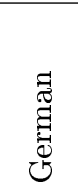 & 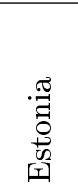 & 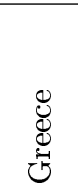 & $\begin{array}{l}\text { 嫣 } \\
\text { की }\end{array}$ & 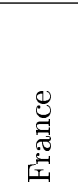 & $\frac{\vec{D}}{ \pm}$ & 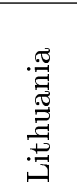 & 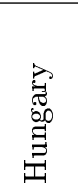 & 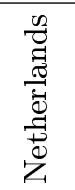 & $\begin{array}{l}\overrightarrow{\vec{J}} \\
\frac{\pi}{0} \\
0\end{array}$ & 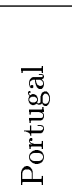 & 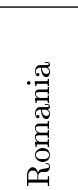 & $\begin{array}{l}\frac{\pi}{\pi} \\
\frac{\pi}{\tilde{\sigma}} \\
\frac{0}{\sigma} \\
\frac{0}{n}\end{array}$ & 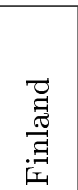 & 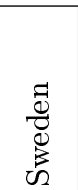 & 菅 \\
\hline Belgiu & & 0.91 & 0.92 & 0.89 & 0.49 & 0.87 & 0.93 & 0.91 & 0.71 & 0.91 & 0.85 & 0.76 & 0.71 & 0.79 & 0.68 & 0.85 & 0.90 & 0.91 \\
\hline Czecl & 0.60 & & 0.94 & .89 & .58 & .94 & .94 & 0.94 & 0.62 & 0.96 & 0.75 & 0.87 & 0.76 & 0.85 & 0.75 & 0.86 & 0.92 & 0.92 \\
\hline Ger1 & 0.45 & 0.35 & & 0.96 & 0.61 & 0.92 & 0.97 & 0.97 & 0.59 & 0.97 & 0.80 & 0.83 & 0.70 & 0.79 & 0.78 & 0.94 & 0.96 & 0.94 \\
\hline Esto & 0.38 & 0.37 & 0.10 & & 0.53 & 0.89 & 0.93 & 0.94 & 0.74 & 0.93 & 0.75 & 0.74 & 0.72 & 0.75 & 0.70 & 0.88 & 0.93 & 0.91 \\
\hline & 0.31 & .52 & 0.17 & 0.25 & & 0.60 & 61 & 0.62 & 0.50 & 0.63 & 0.53 & 0.61 & 0.42 & 0.61 & 0.81 & 0.72 & 0.66 & 0.53 \\
\hline Spain & 0.51 & 0.44 & 0.26 & 0.38 & 0.14 & & 0.93 & 0.95 & 0.42 & 0.95 & 0.74 & 0.88 & 0.83 & 0.83 & 0.75 & 0.84 & 0.90 & 0.95 \\
\hline & 0.76 & 82 & .51 & 0.25 & 0.49 & 0.65 & & 0.97 & 0.59 & 0.95 & 0.83 & 0.83 & 0.69 & 0.78 & 0.74 & 0.91 & 0.96 & 0.93 \\
\hline tal & 0.59 & 0.47 & 0.13 & 0.25 & 0.53 & 0.63 & 0.66 & & 0.53 & 0.98 & 0.77 & 0.86 & 0.79 & 0.80 & 0.79 & 0.92 & 0.95 & 0.96 \\
\hline Lithua & 0.85 & 0.71 & 0.34 & 0.64 & 0.58 & 0.66 & 0.83 & 0.40 & & 0.69 & 0.69 & 0.47 & 0.34 & 0.48 & 0.60 & 0.58 & 0.74 & 0.42 \\
\hline $\mathrm{Hu}$ & 0.39 & 0.51 & -0.0 & 0.03 & 0.70 & 0.19 & 0.47 & 0.54 & 0.55 & & 0.77 & 0.88 & 0.77 & 0.81 & 0.82 & 0.90 & 0.95 & 0.96 \\
\hline Net & 0.51 & 0.74 & 0.64 & 0.10 & 0.27 & 0.22 & 0.63 & 0.33 & 0.45 & 0.32 & & 0.60 & 0.50 & 0.61 & 0.60 & 0.76 & 0.79 & 0.76 \\
\hline & 0.61 & 0.80 & 0.39 & 0.35 & 0.57 & 0.41 & 0.79 & 0.48 & 0.74 & 0.57 & 0.59 & & 0.71 & 0.76 & 0.74 & 0.79 & 0.80 & 0.87 \\
\hline & 0.48 & 0.19 & 0.10 & 0.23 & 0.57 & 0.38 & 0.39 & 0.32 & 0.61 & 0.24 & 0.10 & 0.12 & & 0.83 & 0.59 & 0.65 & 0.67 & 0.76 \\
\hline & 0.86 & 0.75 & 0.17 & 0.61 & 0.54 & 0.74 & 0.79 & 0.66 & 0.85 & 0.70 & 0.44 & 0.84 & 0.48 & & 0.77 & 0.78 & 0.73 & 0.74 \\
\hline & 0.84 & 0.77 & 0.48 & 0.09 & 0.73 & 0.38 & 0.90 & 0.51 & 0.81 & 0.73 & 0.64 & 0.79 & 0.63 & 0.71 & & 0.83 & 0.77 & 0.71 \\
\hline & 0.85 & 0.66 & 0.66 & 0.17 & 0.48 & 0.35 & 0.77 & 0.36 & 0.73 & 0.42 & 0.68 & 0.71 & 0.29 & 0.68 & 0.85 & & 0.91 & 0.85 \\
\hline Sweden & 0.50 & 0.60 & 0.08 & 0.17 & 0.14 & 0.26 & 0.31 & 0.46 & 0.45 & 0.46 & 0.41 & 0.49 & 0.23 & 0.69 & 0.34 & 0.39 & & 0.92 \\
\hline UK & 0.42 & 0.25 & 0.33 & 0.58 & 0.16 & 0.68 & 0.41 & 0.38 & 0.33 & 0.16 & 0.02 & 0.43 & -0.1 & 0.48 & 0.02 & 0.12 & 0.22 & \\
\hline
\end{tabular}


As in Table IV, but for smoothing parameter $\lambda$ corresponding to 10 years.

TABLE V

\begin{tabular}{|c|c|c|c|c|c|c|c|c|c|c|c|c|c|c|c|c|c|c|}
\hline & 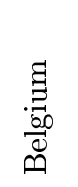 & 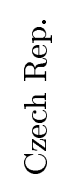 & 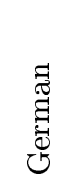 & 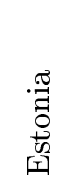 & $\begin{array}{l}\mathscr{U} \\
\mathbb{U} \\
\stackrel{U}{U}\end{array}$ & 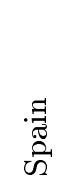 & 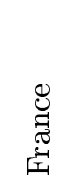 & $\frac{\vec{\pi}}{ \pm}$ & 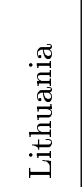 & $\begin{array}{l}\vec{B} \\
\infty \\
\dot{\sigma} \\
\Xi \\
\Xi\end{array}$ & 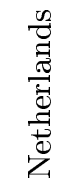 & $\begin{array}{l}\vec{Z} \\
\stackrel{\sigma}{0} \\
0 \\
0\end{array}$ & 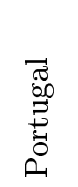 & 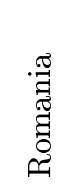 & $\begin{array}{l}\frac{\pi}{\tilde{q}} \\
\frac{\pi}{\tilde{\sigma}} \\
\frac{0}{\sigma}\end{array}$ & 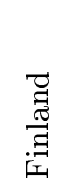 & 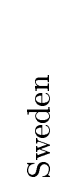 & 菅 \\
\hline Belgium & & 0.90 & 0.93 & 0.81 & 0.44 & 0.81 & 0.92 & 0.92 & 0.53 & 0.88 & 0.87 & 0.84 & 0.56 & 0.72 & 0.57 & 0.87 & 0.90 & 0.89 \\
\hline Czech Rep. & 0.75 & & 0.94 & 84 & 64 & 0.95 & 0.96 & 0.96 & 0.58 & 0.98 & 0.73 & 0.87 & 0.69 & 0.80 & 0.68 & 0.91 & 0.94 & 0.94 \\
\hline Germany & 0.38 & 0.46 & & 0.91 & 0.52 & 0.85 & 0.98 & 0.96 & 0.43 & 0.94 & 0.82 & 0.86 & 0.57 & 0.77 & 0.65 & 0.94 & 0.97 & 0.89 \\
\hline Estonia & 0.45 & 0.46 & -0.2 & & 0.35 & 0.75 & 0.90 & 0.86 & 0.77 & 0.83 & 0.74 & 0.74 & 0.48 & 0.60 & 0.47 & 0.80 & 0.93 & 0.80 \\
\hline Gre & 0.52 & 0.70 & 0.33 & 0.36 & & 0.73 & 0.56 & 0.58 & 0.40 & 0.70 & 0.33 & 0.51 & 0.51 & 0.67 & 0.77 & 0.69 & 0.53 & 0.58 \\
\hline Spain & 0.78 & 0.71 & 0.12 & 0.68 & 0.55 & & 0.90 & 0.91 & 0.39 & 0.97 & 0.62 & 0.82 & 0.75 & 0.76 & 0.66 & 0.84 & 0.86 & 0.93 \\
\hline Fran & 0.89 & 0.89 & 45 & 0.37 & 0.55 & 0.86 & & 0.96 & 0.44 & 0.95 & 0.80 & 0.85 & 0.58 & 0.76 & 0.61 & 0.92 & 0.97 & 0.91 \\
\hline taly & 0.72 & 0.54 & 0.35 & 0.17 & 0.50 & 0.60 & 0.68 & & 0.39 & 0.97 & 0.77 & 0.86 & 0.72 & 0.80 & 0.69 & 0.92 & 0.95 & 0.94 \\
\hline Lithua & 0.75 & 0.84 & 0.18 & 0.82 & 0.69 & 0.88 & 0.90 & 0.28 & & 0.61 & 0.53 & 0.43 & 0.24 & 0.30 & 0.40 & 0.38 & 0.69 & 0.26 \\
\hline Hung & 0.49 & 0.61 & 0.06 & 0.42 & 0.88 & 0.58 & 0.52 & 0.44 & 0.65 & & 0.71 & 0.87 & 0.69 & 0.77 & 0.71 & 0.91 & 0.93 & 0.96 \\
\hline Netherlands & 0.55 & 0.66 & 0.46 & 0.48 & 0.25 & 0.52 & 0.63 & 0.46 & 0.32 & 0.30 & & 0.65 & 0.39 & 0.61 & 0.51 & 0.77 & 0.80 & 0.69 \\
\hline Poland & 0.73 & .88 & 0.56 & 0.38 & 0.61 & 0.65 & 0.90 & 0.50 & 0.83 & 0.51 & 0.58 & & 0.47 & 0.63 & 0.56 & 0.81 & 0.85 & 0.86 \\
\hline Portugal & 0.67 & 0.59 & 0.48 & 0.04 & 0.81 & 0.46 & 0.54 & 0.58 & 0.50 & 0.64 & 0.07 & 0.44 & & 0.77 & 0.62 & 0.59 & 0.54 & 0.69 \\
\hline & 0.87 & 87 & 0.25 & 0.60 & 0.66 & 0.81 & 0.91 & 0.48 & 0.91 & 0.73 & 0.33 & 0.89 & 0.58 & & 0.81 & 0.85 & 0.68 & 0.68 \\
\hline Slovakia & 0.64 & 0.70 & 0.43 & 0.07 & 0.71 & 0.29 & 0.68 & 0.24 & 0.53 & 0.75 & 0.33 & 0.76 & 0.59 & 0.61 & & 0.78 & 0.62 & 0.59 \\
\hline & 0.83 & 0.81 & 0.55 & 0.54 & 0.55 & 0.69 & 0.82 & 0.49 & 0.67 & 0.57 & 0.73 & 0.82 & 0.43 & 0.73 & 0.59 & & 0.91 & 0.83 \\
\hline Sweden & 0.55 & 0.49 & 0.30 & -0.0 & 0.17 & 0.24 & 0.37 & 0.59 & 0.20 & 0.28 & 0.40 & 0.40 & 0.44 & 0.50 & 0.28 & 0.50 & & 0.90 \\
\hline UK & 0.52 & 0.47 & 0.10 & 0.80 & 0.34 & 0.81 & 0.68 & 0.34 & 0.74 & 0.32 & 0.43 & 0.63 & -0.0 & 0.58 & 0.01 & 0.46 & 0.03 & \\
\hline
\end{tabular}

As in Table IV, but for the smoothing parameter $\lambda$ corresponding to 15 years.

TABLE VI

\begin{tabular}{|c|c|c|c|c|c|c|c|c|c|c|c|c|c|c|c|c|c|c|}
\hline & $\begin{array}{l}\text { 园 } \\
\stackrel{50}{00} \\
\stackrel{0}{D}\end{array}$ & 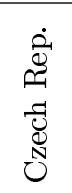 & 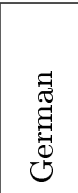 & 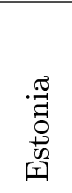 & 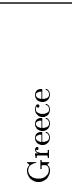 & $\begin{array}{l}\text { 跉 } \\
\text { की }\end{array}$ & 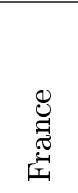 & $\frac{\vec{\pi}}{\stackrel{\pi}{ \pm}}$ & 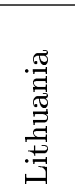 & 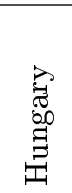 & 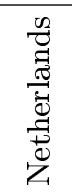 & $\begin{array}{l}\vec{\sigma} \\
\frac{\pi}{0} \\
0\end{array}$ & 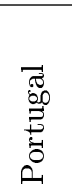 & 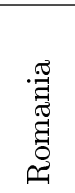 & $\begin{array}{l}\frac{\pi}{\tilde{n}} \\
\frac{\pi}{\tilde{\sigma}} \\
\frac{0}{n}\end{array}$ & 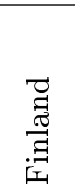 & 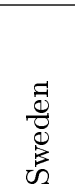 & 岶 \\
\hline Belgi & & 0.84 & 0.89 & 0.66 & 0.42 & 0.69 & 0.79 & 0.85 & 0.43 & 0.78 & 0.87 & 0.87 & 0.45 & 0.64 & 0.57 & 0.86 & 0.85 & 0.74 \\
\hline Czech Rep. & 0.87 & & 0.91 & 0.80 & .72 & .94 & 90 & 0.94 & 0.66 & 0.98 & 0.64 & 0.83 & 0.70 & 0.69 & 0.70 & 0.89 & 0.94 & 0.92 \\
\hline Germany & 0.28 & 0.44 & & 0.84 & 0.48 & 0.80 & 0.95 & 0.95 & 0.43 & 0.88 & 0.78 & 0.83 & 0.54 & 0.75 & 0.63 & 0.93 & 0.95 & 0.83 \\
\hline Estonia & 0.44 & 0.67 & -0.2 & & 0.40 & 0.72 & 0.85 & 0.81 & 0.82 & 0.80 & 0.60 & 0.62 & 0.48 & 0.44 & 0.42 & 0.70 & 0.90 & 0.77 \\
\hline Gre & 0.54 & 0.86 & 0.27 & 0.64 & & 0.80 & 0.53 & 0.58 & 0.59 & 0.78 & 0.25 & 0.50 & 0.59 & 0.50 & 0.75 & 0.65 & 0.58 & 0.64 \\
\hline Spain & 0.62 & 0.85 & 0.09 & 0.77 & 0.87 & & 0.88 & 0.90 & 0.49 & 0.97 & 0.46 & 0.72 & 0.77 & 0.66 & 0.67 & 0.81 & 0.84 & 0.92 \\
\hline & 0.87 & 0.96 & .38 & 0.52 & 0.72 & 0.84 & & 0.95 & 0.45 & 0.90 & 0.66 & 0.75 & 0.59 & 0.73 & 0.59 & 0.88 & 0.92 & 0.90 \\
\hline Italy & 0.76 & 0.81 & 0.38 & 0.46 & 0.79 & 0.77 & 0.81 & & 0.42 & 0.94 & 0.69 & 0.81 & 0.72 & 0.76 & 0.70 & 0.91 & 0.93 & 0.93 \\
\hline Litl & 0.83 & 0.87 & .32 & 0.74 & 0.74 & 0.78 & 0.92 & 0.57 & & 0.70 & 0.39 & 0.42 & 0.35 & 0.14 & 0.40 & 0.37 & 0.73 & 0.36 \\
\hline $\mathrm{Hur}$ & 0.48 & 0.79 & 0.02 & 0.74 & 0.95 & 0.88 & 0.64 & 0.70 & 0.69 & & 0.58 & 0.80 & 0.72 & 0.66 & 0.72 & 0.87 & 0.92 & 0.95 \\
\hline Net & 0.71 & 0.84 & .35 & 0.77 & 0.66 & 0.80 & 0.83 & 0.69 & 0.59 & 0.66 & & 0.67 & 0.27 & 0.52 & 0.47 & 0.74 & 0.73 & 0.52 \\
\hline & 0.74 & 0.88 & 0.51 & 0.34 & 0.48 & 0.51 & 0.87 & 0.55 & 0.88 & 0.32 & 0.70 & & 0.39 & 0.57 & 0.56 & 0.82 & 0.83 & 0.74 \\
\hline Port & 0.89 & 0.88 & 0.56 & 0.50 & 0.91 & 0.78 & 0.85 & 0.88 & 0.72 & 0.81 & 0.60 & 0.67 & & 0.68 & 0.64 & 0.57 & 0.54 & 0.73 \\
\hline & 0.91 & 0.85 & 0.43 & 0.53 & 0.71 & 0.67 & 0.90 & 0.65 & 0.94 & 0.69 & 0.51 & 0.91 & 0.76 & & 0.77 & 0.81 & 0.58 & 0.63 \\
\hline Slovaki & 0.73 & 0.62 & 0.56 & 0.09 & 0.58 & 0.32 & 0.63 & 0.45 & 0.56 & 0.55 & 0.37 & 0.76 & 0.64 & 0.71 & & 0.78 & 0.62 & 0.59 \\
\hline & 0.88 & 0.95 & 0.44 & 0.79 & 0.82 & 0.89 & 0.95 & 0.78 & 0.80 & 0.80 & 0.89 & 0.84 & 0.80 & 0.78 & 0.55 & & 0.88 & 0.77 \\
\hline Sweden & 0.72 & 0.55 & 0.36 & -0.0 & 0.22 & 0.21 & 0.49 & 0.60 & 0.37 & 0.19 & 0.40 & 0.51 & 0.60 & 0.58 & 0.46 & 0.50 & & 0.86 \\
\hline UK & 0.35 & 0.57 & -0.0 & 0.84 & 0.52 & 0.77 & 0.64 & 0.38 & 0.63 & 0.53 & 0.65 & 0.51 & 0.28 & 0.42 & -0.0 & 0.64 & -0.0 & \\
\hline
\end{tabular}


As in Table IV, but for the smoothing parameter $\lambda$ corresponding to 20 years.

\begin{tabular}{|c|c|c|c|c|c|c|c|c|c|c|c|c|c|c|c|c|c|c|}
\hline & 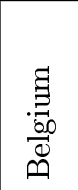 & 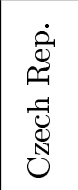 & 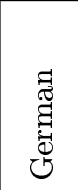 & 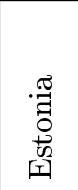 & 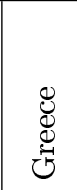 & 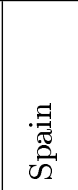 & 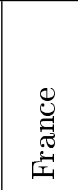 & $\frac{\vec{D}}{\mathbb{N}}$ & 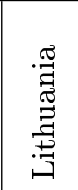 & 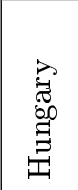 & 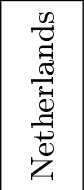 & $\begin{array}{l}\overrightarrow{0} \\
\frac{\sigma}{0} \\
0\end{array}$ & 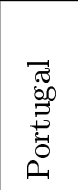 & 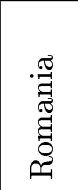 & 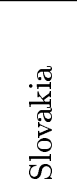 & 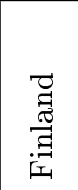 & 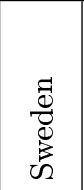 & 茨 \\
\hline Belgium & & 0.82 & 0.81 & 0.60 & 0.50 & 0.60 & 0.61 & 0.76 & 0.48 & 0.76 & \begin{tabular}{|l|}
0.89 \\
\end{tabular} & \begin{tabular}{|l|}
0.89 \\
\end{tabular} & 0.39 & 0.41 & 0.59 & 0.84 & 0.84 & 0.61 \\
\hline Czech Rep. & 0.87 & & 0.85 & 0.79 & 0.78 & 0.89 & 0.79 & 0.90 & 0.73 & 0.98 & 0.64 & 0.83 & 0.68 & 0.47 & 0.72 & 0.86 & 0.94 & 0.86 \\
\hline Germany & 0.26 & 0.42 & & 0.81 & 0.43 & 0.74 & 0.91 & 0.93 & 0.42 & 0.83 & 0.71 & 0.77 & 0.54 & 0.68 & 0.62 & 0.88 & 0.90 & 0.80 \\
\hline Estonia & 0.40 & 0.82 & -0.1 & & 0.47 & 0.71 & 0.80 & 0.79 & 0.84 & 0.80 & 0.54 & 0.58 & 0.51 & 0.30 & 0.43 & 0.66 & 0.89 & 0.77 \\
\hline Greece & 0.40 & 0.88 & 0.29 & 0.76 & & 0.76 & 0.42 & 0.56 & 0.71 & 0.81 & 0.34 & 0.57 & 0.57 & 0.21 & 0.75 & 0.65 & 0.66 & 0.59 \\
\hline Spain & 0.44 & 0.88 & 0.16 & 0.83 & 0.95 & & 0.86 & 0.90 & 0.54 & 0.93 & 0.40 & 0.64 & 0.76 & 0.49 & 0.65 & 0.82 & 0.80 & 0.90 \\
\hline France & 0.80 & 0.98 & 0.38 & 0.68 & 0.73 & 0.81 & & 0.93 & 0.42 & 0.81 & 0.51 & 0.59 & 0.60 & 0.67 & 0.53 & 0.82 & 0.81 & 0.88 \\
\hline Italy & 0.61 & 0.89 & 0.40 & 0.68 & 0.90 & 0.88 & 0.85 & & 0.46 & 0.90 & 0.62 & 0.74 & 0.71 & 0.64 & 0.68 & 0.90 & 0.89 & 0.91 \\
\hline Lithuania & 0.87 & 0.86 & 0.44 & 0.70 & 0.68 & 0.68 & 0.92 & 0.64 & & 0.76 & 0.41 & 0.48 & 0.40 & -0.0 & 0.46 & 0.42 & 0.78 & 0.42 \\
\hline Hungary & 0.35 & 0.85 & 0.04 & 0.86 & 0.95 & 0.93 & 0.68 & 0.81 & 0.64 & & 0.57 & 0.78 & 0.72 & 0.46 & 0.74 & 0.84 & 0.93 & 0.91 \\
\hline Netherlands & 0.77 & 0.92 & 0.40 & 0.84 & 0.74 & 0.81 & 0.90 & 0.79 & 0.71 & 0.75 & & 0.73 & 0.21 & 0.32 & 0.50 & 0.72 & 0.73 & 0.41 \\
\hline Poland & 0.77 & 0.82 & 0.49 & 0.31 & 0.36 & 0.38 & 0.79 & 0.47 & 0.89 & 0.18 & 0.74 & & 0.35 & 0.35 & 0.59 & 0.80 & 0.83 & 0.62 \\
\hline Portugal & 0.91 & 0.94 & 0.58 & 0.69 & 0.86 & 0.81 & 0.93 & 0.91 & 0.80 & 0.81 & 0.79 & 0.73 & & 0.59 & 0.64 & 0.54 & 0.54 & 0.75 \\
\hline Romania & 0.93 & 0.81 & 0.53 & 0.52 & 0.64 & 0.59 & 0.87 & 0.66 & 0.95 & 0.61 & 0.62 & 0.92 & 0.80 & & 0.60 & 0.63 & 0.38 & 0.54 \\
\hline Slovakia & 0.78 & 0.58 & 0.62 & 0.17 & 0.49 & 0.32 & 0.60 & 0.46 & 0.61 & 0.45 & 0.43 & 0.78 & 0.64 & 0.75 & & 0.77 & 0.65 & 0.57 \\
\hline Finland & 0.87 & 0.98 & 0.47 & 0.85 & 0.82 & 0.86 & 0.98 & 0.85 & 0.84 & 0.81 & 0.95 & 0.82 & 0.90 & 0.79 & 0.55 & & 0.86 & 0.73 \\
\hline Sweden & 0.77 & 0.45 & 0.30 & -0.0 & 0.01 & 0.00 & 0.40 & 0.33 & 0.41 & -0.0 & 0.37 & 0.57 & 0.54 & 0.59 & 0.52 & 0.44 & & 0.81 \\
\hline UK & 0.21 & 0.70 & 0.02 & 0.89 & 0.73 & 0.85 & 0.67 & 0.61 & 0.56 & 0.74 & 0.72 & 0.35 & 0.48 & 0.38 & 0.00 & 0.70 & -0.2 & \\
\hline
\end{tabular}

TABLE VIII

Sample correlations $\operatorname{corr}\left(C_{t}, P_{t+n}\right)$ between cycles in total credit $C_{t}$ and production $P_{t}$, with shift $n=-8,-7, \ldots, 0,1,2, \ldots, 8$.

\begin{tabular}{|c|c|c|c|c|c|c|c|c|c|c|c|c|c|c|c|c|c|c|c|}
\hline & & 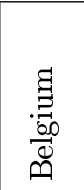 & 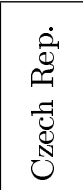 & 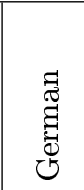 & 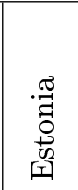 & 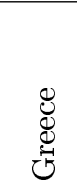 & $\begin{array}{l}\text { 嫣 } \\
\text { की }\end{array}$ & 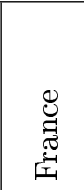 & $\frac{\vec{\pi}}{\oplus}$ & 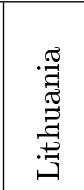 & $\begin{array}{l}\overrightarrow{\tilde{J}} \\
\infty \\
\Xi \\
\Xi \\
\Xi\end{array}$ & 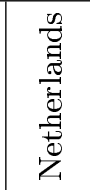 & $\begin{array}{l}\overrightarrow{\vec{T}} \\
\frac{\vec{\pi}}{0} \\
0\end{array}$ & 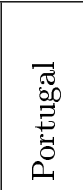 & 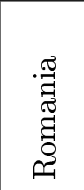 & 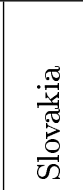 & $\begin{array}{l}\overrightarrow{\widetilde{J}} \\
\underset{\tilde{\sigma}}{\Xi} \\
\stackrel{\Xi}{\mid}\end{array}$ & 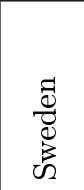 & 岶 \\
\hline \multicolumn{20}{|c|}{ Smoothing parameter $\lambda$ corresponds to 5 years } \\
\hline \multirow{9}{*}{ 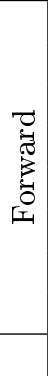 } & 8 & -0.37 & -0.52 & -0.50 & 0.12 & -0.35 & -0.03 & -0.47 & -0.15 & -0.36 & -0.51 & -0.57 & -0.72 & -0.25 & -0.29 & -0.53 & -0.68 & -0.18 & 0.02 \\
\hline & 7 & -0.33 & -0.45 & -0.51 & 0.17 & -0.32 & 0.04 & -0.40 & -0.04 & -0.28 & -0.44 & -0.54 & -0.68 & -0.16 & -0.20 & -0.45 & -0.61 & -0.04 & 0.05 \\
\hline & 6 & -0.27 & -0.38 & -0.51 & 0.21 & -0.29 & 0.10 & -0.32 & 0.07 & -0.18 & -0.35 & -0.49 & -0.62 & -0.07 & -0.09 & -0.37 & -0.53 & 0.10 & 0.09 \\
\hline & 5 & -0.20 & -0.29 & -0.49 & 0.25 & -0.24 & 0.17 & -0.23 & 0.19 & -0.08 & -0.25 & -0.43 & -0.55 & 0.01 & 0.02 & -0.28 & -0.44 & 0.24 & 0.13 \\
\hline & 4 & -0.13 & -0.19 & -0.46 & 0.28 & -0.19 & 0.24 & -0.13 & 0.30 & 0.02 & -0.14 & -0.36 & -0.46 & 0.10 & 0.13 & -0.17 & -0.33 & 0.37 & 0.17 \\
\hline & 3 & -0.05 & -0.09 & -0.42 & 0.31 & -0.13 & 0.30 & -0.02 & 0.41 & 0.12 & -0.02 & -0.26 & -0.37 & 0.17 & 0.25 & -0.06 & -0.22 & 0.48 & 0.21 \\
\hline & 2 & 0.03 & 0.02 & -0.37 & 0.33 & -0.07 & 0.37 & 0.10 & 0.52 & 0.22 & 0.10 & -0.17 & -0.26 & 0.25 & 0.36 & 0.05 & -0.09 & 0.57 & 0.25 \\
\hline & 1 & 0.11 & 0.13 & -0.30 & 0.35 & 0.01 & 0.43 & 0.22 & 0.61 & 0.31 & 0.21 & -0.07 & -0.15 & 0.31 & 0.46 & 0.17 & 0.03 & 0.64 & 0.29 \\
\hline & 0 & 0.20 & 0.23 & -0.23 & 0.36 & 0.08 & 0.48 & 0.33 & 0.70 & 0.38 & 0.32 & 0.03 & -0.03 & 0.38 & 0.56 & 0.28 & 0.16 & 0.69 & 0.31 \\
\hline \multirow{8}{*}{ 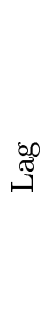 } & -1 & 0.29 & 0.33 & -0.15 & 0.37 & 0.16 & 0.52 & 0.43 & 0.77 & 0.45 & 0.42 & 0.12 & 0.08 & 0.43 & 0.65 & 0.40 & 0.28 & 0.71 & 0.34 \\
\hline & -2 & 0.37 & 0.40 & -0.07 & 0.37 & 0.24 & 0.55 & 0.52 & 0.83 & 0.50 & 0.51 & 0.21 & 0.19 & 0.47 & 0.73 & 0.50 & 0.39 & 0.71 & 0.35 \\
\hline & -3 & 0.46 & 0.47 & 0.02 & 0.36 & 0.31 & 0.57 & 0.60 & 0.88 & 0.53 & 0.57 & 0.28 & 0.29 & 0.49 & 0.80 & 0.60 & 0.49 & 0.69 & 0.35 \\
\hline & -4 & 0.54 & 0.52 & 0.10 & 0.36 & 0.37 & 0.59 & 0.67 & 0.90 & 0.55 & 0.62 & 0.35 & 0.37 & 0.51 & 0.85 & 0.68 & 0.59 & 0.64 & 0.35 \\
\hline & -5 & 0.61 & 0.57 & 0.19 & 0.34 & 0.42 & 0.60 & 0.72 & 0.91 & 0.55 & 0.65 & 0.41 & 0.45 & 0.51 & 0.88 & 0.75 & 0.66 & 0.58 & 0.35 \\
\hline & -6 & 0.67 & 0.60 & 0.27 & 0.32 & 0.45 & 0.60 & 0.76 & 0.90 & 0.53 & 0.66 & 0.46 & 0.51 & 0.50 & 0.90 & 0.81 & 0.72 & 0.51 & 0.34 \\
\hline & -7 & 0.72 & 0.62 & 0.34 & 0.30 & 0.48 & 0.59 & 0.78 & 0.86 & 0.50 & 0.65 & 0.50 & 0.56 & 0.49 & 0.90 & 0.84 & 0.76 & 0.43 & 0.32 \\
\hline & -8 & 0.74 & 0.62 & 0.41 & 0.28 & 0.48 & 0.57 & 0.78 & 0.81 & 0.46 & 0.62 & 0.52 & 0.60 & 0.46 & 0.88 & 0.86 & 0.79 & 0.35 & 0.30 \\
\hline
\end{tabular}


TABLE VIII cont.

\begin{tabular}{|c|c|c|c|c|c|c|c|c|c|c|c|c|c|c|c|c|c|c|c|}
\hline \multicolumn{20}{|c|}{ Smoothing parameter $\lambda$ corresponds to 10 years } \\
\hline \multirow{17}{*}{ 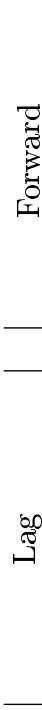 } & 8 & -0.14 & .40 & 0.49 & -0.15 & -0.35 & -0.07 & -0.33 & -0.06 & -0.52 & -0.47 & -0.30 & -0.63 & -0.37 & -0.16 & -0.59 & -0.35 & -0.24 & \\
\hline & 7 & -0.09 & .34 & .47 & -0.11 & .31 & -0.02 & -0.27 & 0.02 & -0.48 & 0.42 & -0.26 & -0.57 & -0.32 & -0.06 & -0.52 & -0.28 & -0.13 & 0.13 \\
\hline & 6 & -0.03 & 0.28 & .45 & -0.07 & .26 & 0.04 & 0.21 & 0.10 & -0.43 & 0.37 & -0.21 & -0.51 & -0.28 & 0.04 & -0.44 & -0.20 & -0.03 & \\
\hline & 5 & 0.02 & -0.22 & .42 & -0.03 & -0.21 & 0.10 & 0.14 & 0.18 & -0.38 & 0.31 & -0.15 & -0.44 & -0.23 & 0.14 & -0.36 & -0.12 & 0.07 & 0.24 \\
\hline & 4 & 0.08 & 0.15 & .39 & 0.01 & -0.16 & 0.15 & -0.07 & 0.26 & -0.33 & 0.24 & -0.08 & -0.36 & -0.19 & 0.24 & -0.28 & -0.03 & .16 & \\
\hline & 3 & 0.13 & 0.08 & .34 & 0.05 & -0.10 & 0.21 & 0.00 & 0.34 & -0.28 & 0.17 & 0.00 & -0.28 & -0.14 & 0.33 & -0.18 & 0.06 & 0.24 & \\
\hline & 2 & 0.19 & -0.01 & -0.30 & 0.09 & -0.05 & 0.27 & 0.08 & 0.40 & -0.23 & 0.10 & 0.08 & -0.19 & -0.10 & 0.42 & -0.09 & 0.15 & .32 & 40 \\
\hline & 1 & 0.24 & 0.06 & -0.24 & 0.12 & 0.01 & 0.32 & 0.15 & 0.47 & -0.19 & 0.03 & 0.16 & -0.10 & -0.06 & 0.51 & 0.01 & 0.25 & 0.37 & 0.45 \\
\hline & 0 & 0.29 & 0.13 & -0.18 & 0.16 & 0.07 & 0.38 & 0.22 & 0.52 & -0.14 & 0.03 & 0.24 & -0.02 & -0.02 & 0.58 & 0.11 & 0.34 & .42 & .50 \\
\hline & -1 & 0.34 & 0.20 & -0.12 & 0.19 & 0.13 & 0.43 & 0.29 & 0.57 & -0.10 & 0.11 & 0.32 & 0.07 & 0.03 & 0.65 & .20 & 0.43 & .46 & .53 \\
\hline & -2 & 39 & 0.26 & -0 . & 0.23 & 0.20 & & 0 & & 5 & & & & & .70 & .29 & & 48 & \\
\hline & -3 & 0.43 & 0.32 & 0.01 & 0.26 & 0.26 & 0.52 & 0.41 & 0.64 & -0.01 & 0.23 & 0.45 & 0.24 & .12 & 0.75 & 0.38 & 0.59 & .49 & .58 \\
\hline & -4 & 0.47 & 0.37 & $0 .($ & 0.29 & 0.31 & & & & & & & & & .79 & 46 & & 49 & \\
\hline & -5 & 0.51 & 0.41 & 0.13 & 0.31 & 0.37 & 0.60 & 0.50 & 0.67 & 0.06 & 0.33 & 0.56 & 0.39 & 0.20 & 0.81 & 0.54 & 0.71 & .48 & 0.62 \\
\hline & -6 & 54 & 0.46 & 9 & 0.34 & 0.42 & 0.6 & 0 & & 9 & & & & & 1.82 & .60 & & .45 & \\
\hline & -7 & 0.56 & 0.49 & .24 & 0.36 & 0.46 & 0.65 & 0.57 & 0.64 & 0.12 & 0.39 & 0.62 & 0.51 & 0.26 & 0.82 & .66 & 0.80 & .42 & .63 \\
\hline & -8 & 58 & .52 & 29 & 0 & 0.50 & 0.67 & 0.59 & 0.60 & 0.14 & 0.41 & 0.63 & 0.56 & & 0.82 & 0.71 & & 38 & \\
\hline \multicolumn{20}{|c|}{ Smoothing parameter $\lambda$ corresponds to 15 years } \\
\hline \multirow{17}{*}{ 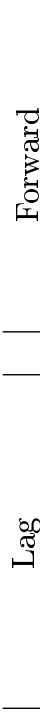 } & 8 & 0.01 & 0.35 & 0.52 & -0.19 & -0.14 & -0.15 & -0.44 & -0.19 & -0.62 & -0.17 & -0.01 & -0.49 & -0.40 & -0.31 & -0.67 & -0.10 & -0.36 & 0.04 \\
\hline & 7 & 0.05 & .30 & .51 & 0.15 & .11 & -0.1 & 0 & & -0.59 & & & & & .22 & -0.61 & 0.05 & .29 & \\
\hline & 6 & 0.09 & -0.25 & .49 & -0.11 & -0.07 & -0.08 & 0.35 & -0.08 & -0.55 & & 97 & & & -0.13 & -0.55 & 0.00 & -0.22 & 14 \\
\hline & 5 & 0.13 & -0.20 & .46 & -0.08 & 0.04 & -0.04 & 0.30 & -0 . & -0.52 & 8 & & -0. & & -0.04 & -0.48 & 0.06 & .15 & \\
\hline & 4 & 0.18 & .14 & .43 & -0.04 & 0.00 & 0.00 & -0.25 & 0. & -0.48 & & 0. & & & 0.04 & -0.41 & 0.12 & 0.08 & 25 \\
\hline & 3 & 0.22 & .08 & .40 & -0.01 & 0.03 & 0.04 & 0.19 & & -0.44 & 1 & 0.23 & -0. & & .13 & -0.33 & 0.18 & .01 & 30 \\
\hline & 2 & 0.26 & .03 & & 0.03 & 0.07 & & -0 . & & -0. & 0.02 & & & & 0.21 & & & .04 & \\
\hline & 1 & 0.30 & 0.03 & 0.31 & 0.06 & 0.10 & 0.12 & -0.08 & 0.16 & -0.36 & .06 & 0.35 & -0.02 & -0.24 & 0.28 & -0.17 & 0.30 & .09 & 0.40 \\
\hline & 0 & 0.34 & 0.09 & 0.26 & 0.10 & 0.14 & & 3 & 0.20 & -0.32 & 0.0 & 0 & 0.05 & & .35 & -0.09 & .36 & .13 & \\
\hline & -1 & 0.38 & 0.14 & -0.21 & 0.13 & 0.19 & 0.20 & 0.03 & 0.24 & -0.28 & 0.14 & 0. & .13 & -0.17 & 0.41 & -0.01 & & .16 & \\
\hline & -2 & .41 & 0.20 & 5 & & 0.2 & & & & & & & 20 & & .46 & & & .19 & \\
\hline & -3 & 0.44 & 0.25 & & 0.19 & 0.29 & & & & & 0 & & 28 & & 51 & .16 & & .21 & \\
\hline & -4 & .47 & 0.30 & -0. & 0.22 & 0.34 & & 0.1 & & -0.16 & 0.26 & & .34 & & .54 & .23 & & .22 & 59 \\
\hline & -5 & 0.49 & 0.35 & & 0.25 & 0.38 & & 0.23 & & -0.12 & 0.3 & & & & 0.57 & .31 & & .21 & \\
\hline & -6 & 0.52 & 0.39 & & 0.27 & 0.43 & 2 & 0.27 & & -0.09 & 33 & 0.60 & .47 & & .59 & .38 & 0.62 & .21 & 63 \\
\hline & -7 & 0.53 & 0.42 & & & 0.47 & & & & & & & & & 60 & & & .19 & \\
\hline & -8 & 0.55 & 0.46 & .15 & 0.32 & 0.51 & 0.49 & 0.33 & 0.35 & -0.02 & 0.38 & 0.60 & 0.57 & 0.08 & 0.61 & 0.50 & 0.66 & 0.17 & 0.66 \\
\hline \multicolumn{20}{|c|}{ moothing parameter $\lambda$ corresponds to 20 years } \\
\hline \multirow{17}{*}{ 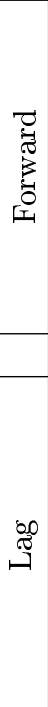 } & 8 & 0.00 & .20 & .52 & -0.13 & 0.19 & -0.07 & -0.53 & -0.17 & -0.60 & 0.10 & 0.18 & -0.43 & -0.38 & -0.39 & -0.66 & -0.01 & -0.49 & .01 \\
\hline & 7 & 0.04 & -0.15 & 0.51 & -0.10 & 0.21 & -0.04 & -0.50 & -0.12 & -0.57 & 0.1 & 0.22 & -0.38 & -0.37 & -0.31 & -0.61 & 0.04 & 0.43 & 0.05 \\
\hline & 6 & 0.09 & -0.10 & -0.49 & -0.06 & 0.24 & -0.01 & -0.46 & -0.08 & & 0.14 & 0.25 & -0.32 & & -0.23 & & 0.09 & -0.37 & 0.10 \\
\hline & 5 & 0.13 & -0.05 & -0.47 & -0.03 & 0.26 & 0.03 & -0.42 & -0.03 & -0.50 & 0.16 & 0.30 & -0.27 & -0.33 & -0.15 & -0.48 & 0.14 & -0.31 & 0.14 \\
\hline & 4 & 0.18 & 0.00 & -0.44 & 0.00 & 0.29 & & & & -0.46 & 0.1 & 0. & -0.20 & -0.31 & -0.08 & -0.42 & 0.19 & -0.25 & 0. \\
\hline & 3 & 0.22 & 0.05 & -0.40 & 0.04 & 0.31 & 0.09 & -0.33 & 0.05 & -0.42 & 0.21 & 0.39 & -0.14 & -0.29 & -0.01 & -0.35 & 0.24 & -0.19 & 0.23 \\
\hline & 2 & 0.27 & 0.10 & -0.3 & & 0.3 & & -0.2 & 0.09 & -0.38 & & & -0.07 & -0. & 0.06 & -0.27 & 0.29 & -0.14 & \\
\hline & 1 & 0.31 & 0.15 & -0.32 & 0.10 & 0.35 & 0.15 & -0.25 & 0.13 & -0.35 & 0.25 & 0.48 & 0.00 & -0.26 & 0.13 & -0.20 & 0.34 & -0.09 & 0.32 \\
\hline & 0 & 0.36 & 0.20 & -0.27 & 0.13 & 0.37 & 0.18 & -0.20 & 0.16 & -0.31 & 0.27 & 0.52 & 0.07 & -0.24 & 0.18 & -0.12 & 0.38 & -0.05 & 0.36 \\
\hline & -1 & 0.39 & 0.25 & -0.23 & 0.16 & 0.41 & 0.23 & -0.15 & 0.20 & -0.28 & 0.30 & 0.56 & 0.14 & -0.20 & 0.24 & -0.05 & 0.42 & -0.02 & 0.40 \\
\hline & -2 & 0.43 & 0.29 & -0.18 & 0.18 & 0.45 & .28 & -0.10 & 0.23 & -0.24 & 34 & 0.58 & 0.20 & -0.16 & 0.29 & 0.03 & 0.46 & 0.01 & 0.44 \\
\hline & -3 & 0.46 & 0.34 & -0.12 & 0.21 & 0.48 & 0.32 & -0.05 & 0.26 & -0.20 & 0.36 & 0.61 & 0.27 & -0.13 & 0.34 & 0.11 & 0.50 & 0.03 & 0.48 \\
\hline & -4 & 0.49 & 0.38 & -0.07 & 0.24 & 0.52 & 0.36 & -0.01 & 0.28 & -0.17 & 0.39 & 0.63 & 0.33 & -0.09 & 0.38 & 0.18 & 0.53 & 0.05 & 0.52 \\
\hline & -5 & 0.52 & 0.42 & -0.02 & 0.26 & 0.55 & 0.40 & 0.03 & 0.30 & -0.13 & 0.42 & 0.65 & 0.39 & -0.05 & 0.40 & 0.25 & 0.56 & 0.06 & 0.55 \\
\hline & -6 & 0.55 & 0.46 & & 0.29 & 0.58 & 0.4 & 0.07 & 0.32 & -0.10 & 0.44 & 0.65 & 0.45 & -0.02 & 0.43 & 0.32 & 0.58 & 0.06 & 0.58 \\
\hline & -7 & 0.57 & 0.49 & & & 0.61 & & 0.11 & 0.32 & -0.07 & 0.46 & & 0.50 & 0.02 & 0.44 & 0.38 & 0.60 & 0.06 & 0.60 \\
\hline & -8 & 0.59 & 0.52 & 0.11 & 0.33 & 0.63 & 0.50 & 0.14 & 0.33 & -0.04 & 0.48 & 0.65 & 0.55 & 0.05 & 0.45 & 0.44 & 0.62 & 0.05 & 0.63 \\
\hline
\end{tabular}




\section{Conclusions}

In this paper we examine the empirical properties of the credit cycle in selected European countries using two alternative nonparametric approaches based on different but much more general assumptions compared to the standard approach. The first approach is based on representing cyclical fluctuations in terms of almost periodic mean function utilising the idea of deterministic cycle; see Harvey [31], Lenart and Pipień [33, 34]. The second approach is based on detrending and nonparametric spectral analysis.

In the empirical part of the paper, we analyse monthly series of the total credit and production using both methods. Using first method we make formal statistical inferences about the properties of the cycles. The subsampling test of the significance of a particular frequency was used to show substantial diversity of the credit cycle across analyzed European countries. In the second approach we extracted cyclical components on the basis of the HP filter to estimate spectral mass concentration.

Empirical results shows that the credit cycle is much longer than the production cycle. This conclusion follows from both methodologies. This result is invariant with respect to the level of development of a particular country and stays the same in case of developed economies as well as in catching-up ones. Also our results confirm strong heterogeneity if the length of cycles across countries. The cyclical fluctuations in the credit seems a country specific features rather than an effect driven by international factors.

Also the correlation analysis leads to comparable conclusions in set of developed and catching-up economies. Except Lithuania the credit cycle precedes production cycle. This result confirms theoretical considerations driven initially by Minsky in 90's; see Minsky [61].

\section{Acknowledgments}

This research was supported by the Polish National Science Centre under decision no. DEC-2014/09/13/HS4/01945.

\section{References}

[1] I. Fisher, Econometrica 1, 337 (1933).

[2] H.P. Minsky, Can "It" Happen Again? Essays on Instability and Finance, Armonk, New York 1982.

[3] D. Delli Gatti, M. Gallegati, B. Greenwald, A. Russo, J.E. Stiglitz, Physica A 370, 68 (2006).

[4] M. Drehmann, C. Borio, K. Tsatsaronis, "Characterising the Financial Cycle: Don't Lose Sight of the Medium Term!", BIS Working Papers No. 380, 2012.

[5] V. Cúrdia, M. Woodford, Credit Frictions and Optimal Monetary Policy, J. Monet. Econom. 84, 30 (2016).

[6] Y. Teranishi, Econom. Lett. 114, 26 (2012).

[7] M. Del Negro, M.P. Giannoni, F. Schorfheide, Am. Econom. J. Macroeconom. 7, 168 (2015).
[8] A.C. Harvey, T.M. Trimbur, Rev. Econom. Statist. 85, 244 (2003).

[9] T.M. Trimbur, J. Time Series Anal. 27, 1 (2006).

[10] S.J. Koopman, N. Shephard, Unobserved Components and Time Series Econometrics, Oxford University Press, Oxford 2015.

[11] M.M. Pelagatti, Time Series Modelling with Unobserved Components, Taylor \& Francis, Boca Raton 2016.

[12] J.V. Azevedo, S.J. Koopman, A. Rua, J. Busin. Econom. Statist. 24, 278 (2006).

[13] A.C. Harvey, T.M. Trimbur, H.K. Van Dijk, J. Econometrics 140, 618 (2007).

[14] Ch. Croux, M. Forni, L. Reichlin, Rev. Econom. Statist. 83, 232 (2001).

[15] J.D. Hamilton, Time Series Analysis, Princeton University Press, New Jersey 1994.

[16] M.B. Priestley, Spectral Analysis and Time Series, Academic Press, London 1981.

[17] Z. Ftiti, Econom. Modell. 27, 468 (2010).

[18] R. Metz, J. Macroeconom. 31, 58 (2009).

[19] A.G. Orlov, Econom. Lett. 91, 222 (2006).

[20] A.G. Orlov, J. Int. Financ. Markets Institut. Money 19, 742 (2009).

[21] M.R. Pakko, Econom. Lett. 84, 341 (2004).

[22] P. McAdam, R. Mestre, Econom. Modell. 25, 1137 (2008).

[23] M. Uebele, A. Ritschl, J. Macroeconom. 31, 35 (2009).

[24] R.J. Hodrick, E.C. Prescott, Postwar U.S. Business Cycles: An Empirical Investigation, J. Money Credit Bank. 29, 1 (1997).

[25] M. Baxter, R.G. King, Rev. Econom. Statist. 81, 575 (1999).

[26] L.J. Christiano, T.J. Fitzgerald, NBER Working Paper Series No. 7257, 1999.

[27] F. Canova, J. Monet. Econom. 41, 475 (1998).

[28] C. Burnside, J. Monet. Econom. 41, 513 (1998).

[29] J.G. Žurbenko, The Spectral Analysis of Time Series, North-Holland, Amsterdam 1986.

[30] Ł. Lenart, Bernoulli 17, 290 (2011).

[31] A.C. Harvey, in: State Space and Unobserved Component Models, Eds. A.C. Harvey, S.J. Koopman, N. Shephard, Cambridge University Press, 2004, p. 102.

[32] K.M. Lee, Filtering Non-Linear State Space Models: Methods and Economic Applications Rozenberg Publ., 2010.

[33] Ł. Lenart, M. Pipień, Acta Phys. Pol. A 123, 70 (2013).

[34] Ł. Lenart, M. Pipień, Central Europ. J. Econom. Modell. Econometr. 7, 169 (2015).

[35] Ł. Lenart, M. Pipień, Central Europ. J. Econom. Modell. Econometr. 9, 201 (2017).

[36] Ł. Lenart, M. Pipień, Folia Oeconom. Cracoviens. 58, 127 (2017). 
[37] E.G. Gladyshev, Sov. Math. 2, 385 (1961).

[38] E. Parzen, M. Pagano, J. Econometr. 9, 137 (1979).

[39] D.R. Osborn, J.P. Smith, J. Busin. Econom. Statist. 9, 117 (1989)

[40] P.H. Franses, Stochastic Trends in Economic Time Series, Oxford University Press, New York 1996.

[41] T. Bollerslev, E. Ghysels, J. Busin. Econom. Statist. 14, 139 (1996).

[42] P.H. Franses, H.P. Boswijk, Statist. Probabil. Lett. 30, 235 (1996).

[43] P. Burridge, A.M. Taylor, J. Econometr. 104, 91 (2001).

[44] Ł. Lenart, M. Pipień, Central Europ. J. Econom. Modell. Econometr. 5, 85 (2013).

[45] Ł. Lenart, J. Multivar. Anal. 115, 252 (2013).

[46] Ł. Lenart, M. Pipień, B. Mazur, Equilibrium Quarterly J. Econom. Econom. Policy 11, 769 (2016).

[47] B. Mazur, Equilibrium Quarterly J. Econom. Econom. Policy 12, 435 (2017).

[49] A. Napolitano, Sign. Process. 120, 385 (2016).

[50] H. Hurd, A.G. Miamee, Periodically Correlated Random Sequences: Spectral Theory and Practice, Wiley, Hoboken (NJ) 2007.

[51] H. Hurd, J. Multivar. Anal. 29, 53 (1989).
[52] H. Hurd, J. Multivar. Anal. 37, 24 (1991).

[53] S. Claessens, M. Ayhan Kose, M.E. Terrones, "Financial Cycles: What? How? When?", 2011, IMF Working Paper, WP $/ 11 / 76$.

[54] C.-M. Apostoaie, S. Percic, Proced. Econom. Fin. 15, 1055 (2014).

[55] J.E. Gomez-Gonzalez, M. Villamizar-Villegas, H.M. Zarate, J.S. Amadar, C. Gaitan-Maldonado, Ensayos sobre Política Económica 33, 176 (2015) (in Spanish).

[56] D. Ladiray, in: Economic Time Series: Modeling and Seasonality, Eds. W.R. Bell, S.H. Holan, T.S. McErloy, Taylor \& Francis, Boca Raton 2012, p. 255.

[57] Ł. Lenart, Dynam. Econometr. Models 15, 27 (2015).

[58] P.J. Brockwell, R.A. Davis, Time Series: Theory and Methods, Springer-Verlag, New York 2002.

[59] M. Loève, Probability Theory, Springer-Verlag, New York 1977

[60] C. Borio, "The Financial Cycle and Macroeconomics: What Have We Learnt?", BIS Working Papers, no. 395, 2012.

[61] H.P. Minsky, in: Evolving Technology and Market Structure: Studies in Schumpeterian Economics, Eds. A. Heertje, M. Perlman, The University of Michigan Press, Ann Arbor 1990. 